\title{
Mechanisms of prion-induced neurodegeneration
}

\author{
PAULA SAÁ ${ }^{1 *}$, DAVID A. HARRIS ${ }^{2}$, LARISA CERVENAKOVA $^{1}$ \\ ${ }^{1}$ Scientific Affairs, Holland Laboratory, American Red Cross, Rockville, MD, USA, and ${ }^{2}$ Department of \\ Biochemistry, Boston University School of Medicine, Boston, MA, USA
}

\begin{abstract}
Transmissible spongiform encephalopathies (TSEs), or prion diseases, are fatal neurodegenerative disorders characterised by long incubation period, short clinical duration, and transmissibility to susceptible species. Neuronal loss, spongiform changes, gliosis and the accumulation in the brain of the misfolded version of a membrane-bound cellular prion protein $\left(\operatorname{PrP}^{\mathrm{C}}\right)$, termed $\mathrm{PrP}^{\mathrm{TSE}}$, are diagnostic markers of these diseases. Compelling evidence links protein misfolding and its accumulation with neurodegenerative changes. Accordingly, several mechanisms of prion-mediated neurotoxicity have been proposed. In this paper, we provide an overview of the recent knowledge on the mechanisms of neuropathogenesis, the neurotoxic PrP species and the possible therapeutic approaches to treat these devastating disorders.
\end{abstract}

\section{Animal and human prion diseases}

The term prion was originally coined by S.B. Prusiner to denote a small proteinaceous infectious particle, which is resistant to most procedures that inactivate nucleic acids (Ref. 1). Prion diseases or transmissible spongiform encephalopathies (TSEs) are fatal neurodegenerative disorders affecting humans and animals (Fig. 1). Human TSEs are often categorised with other protein misfolding neurodegenerative diseases, including Alzheimer's disease (AD), Parkinson's disease, Huntington's disease, fronto-temporal dementia and amyotrophic lateral sclerosis (Ref. 2). These diseases share a common mechanism that involves a conformational change in the structure of the diseaseimplicated protein, leading to self-replicating propagation and subsequent pathological changes within the central nervous system (CNS). However, only TSEs are known to cause infections of epidemic proportions in humans (kuru) and animals [bovine spongiform encephalopathy (BSE)], and be endemically present in domestic (scrapie) and wild animals [chronic wasting disease (CWD)] (Fig. 1).

Human TSEs can be subdivided into three aetiological groups: sporadic, genetic and environmentally acquired (i.e. infectious). Sporadic Creutzfeldt-Jakob disease (sCJD) is the most common form, occurring without any obvious cause with a frequency of 1 case per million people per year worldwide (Ref. 3). Sporadic fatal insomnia (sFI) is a very rare disease described in only approximately 2 dozen cases so far (Refs 3,4$)$. The spectrum has been recently expanded to include variably protease-sensitive prionopathy, a rare sporadic condition recognised in a small number of patients, with certain features resembling Gerstmann-Sträussler-Scheinker syndrome (GSS) (Refs 5, 6, 7, 8). The genetic forms represent 10-15\% of all TSE cases and include familial CJD (fCJD), GSS and fatal familial insomnia (FFI) (Refs 9, 10). These diseases are inherited in an autosomal dominant fashion and are associated with more than 30 pathogenic mutations in the prion protein gene (PRNP) (Ref. 11). The infectious forms include variant CJD (vCJD), presumably resulting from dietary exposure to BSE (Ref. 12), iatrogenic CJD (iCJD) (Ref. 13), and kuru, an almost extinct disease described in cannibalistic tribes of New Guinea (Refs 14, 15, 16, 17). iCJD has been linked to therapeutic treatments with human pituitary hormones (growth hormone and gonadotropin), dura mater, cornea or pericardial grafts unknowingly sourced from CJD-afflicted individuals, and to rare neurosurgical procedures performed with inadequately decontaminated instruments previously used on CJD patients (Refs 13, 18). Recently, the transmission of vCJD has been reported in four instances through the therapeutic use of nonleukoreduced red blood cell concentrates (Refs 13, 19, 20, 21, 22).

Each form of human TSE results in a distinctive phenotype characterised by differences in the age of onset, variability in clinical symptoms, brain pathology and disease duration, and by different $\mathrm{PrP}^{\mathrm{TSE}}$ distribution and deposition patterns [reviewed in (Refs 3, 8, 10, 15, 16, 17, 23)]. The molecular mechanisms of TSE phenotypic heterogeneity are not fully understood, although polymorphisms in the host $P R N P$ gene influence the phenotypic differences and individual susceptibility to certain forms of the disease (Refs 24, 25, 26, 27, 28, 29, 30, $31)$. These polymorphisms also partially explain the origin of biochemically distinct $\operatorname{PrP}^{\mathrm{TSE}}$ conformers substantiating the existence of prion strains in humans (Refs 32, 33, 34) and animals (Refs 35, 36, 37).

In animals, TSEs manifest, among other forms, as scrapie in sheep and goat, BSE (known to the general 


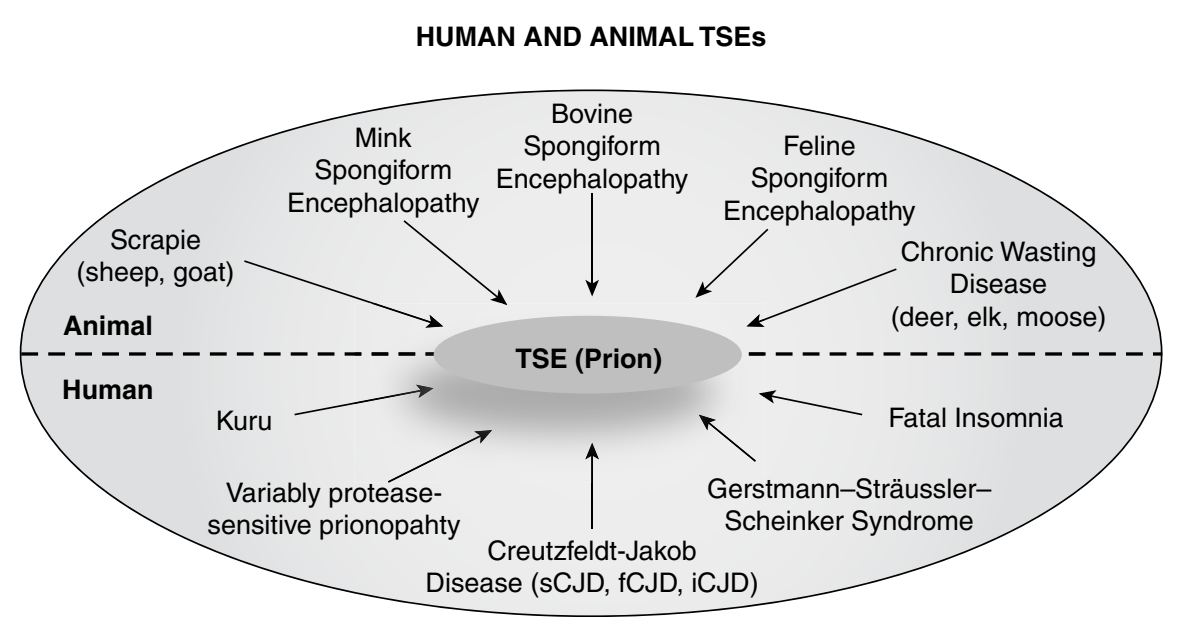

\section{Animal and human transmissible spongiform encephalopathies (TSES)}

Expert Reviews in Molecular Medicine (c) 2016 Cambridge University Press

FIGURE 1

Animal and human TSEs.

public as 'mad cow disease') in cattle, and CWD in cervids (Fig. 1). Animal diseases are relatively easily transmitted within the same species, but cross-species transmissions have been documented as well. BSE is the only animal form of TSE that has been causatively linked to a disease in humans, vCJD (Refs 12, 38). For a complete review on animal prion disease, see Collinge (Ref. 39).

It is widely accepted that the causative agent of TSEs is the prion, which is mainly composed of a misfolded, insoluble, and proteinase $\mathrm{K}(\mathrm{PK})$-resistant protein that is devoid of detectable informational nucleic acid, herein referred to as $\operatorname{PrP}^{\mathrm{TSE}}$ (also known as $\operatorname{PrP}^{\mathrm{Sc}}$, $\operatorname{PrP}^{\text {res }}$ or $\left.\operatorname{PrP}^{\mathrm{d}}\right)(\operatorname{Refs} 1,2,40)$. The exact mechanism(s) of $\mathrm{PrP}^{\mathrm{TSE}}$ generation are not fully understood. According to the current state of knowledge, the main event is the conformational change of $\operatorname{PrP}^{\mathrm{C}}$ into $\operatorname{PrP}^{\mathrm{TSE}}$. This transition occurs under unknown circumstances and gives rise to multiple conformers exhibiting a range of strain-specific phenotypes in afflicted hosts (Ref. 41). Temporal and spatial deposition of $\mathrm{PrP}^{\mathrm{TSE}}$ coincides with a series of pathological events in the brain, resulting in spongiform degeneration, neuronal loss, and gliosis, which constitute the hallmarks of TSEs (Ref. 42). Prions utilise several routes of infection, which determine the length of the silent incubation period in an infected host. Usually, peripheral extra-neural exposures result in incubation phases that are longer than direct intracerebral routes. Factors and mechanisms underlying prion intra- and inter-species transmission leading to neurodegeneration are still under study, but significant progress has been made in the three decades following their discovery.

\section{PrP $^{C}$ function}

$\operatorname{PrP}^{\mathrm{C}}$ is a sialoglycoprotein of 253 amino acids (human $\operatorname{PrP}^{\mathrm{C}}$ ) encoded by a single gene. Post-translational processing in the endoplasmic reticulum (ER), results in the removal of an amino $(\mathrm{N})$-terminal signal sequence peptide (residues 1 to 22), and a carboxi (C)-terminal sequence for the attachment of a glycosyl phosphatidyl inositol (GPI) anchor to Ser-231 (Ref. 43). The N-terminal domain of the protein contains a repetitive sequence (residues 52-91) of eight amino acids, the so-called octapeptide repeats (PHGGGWGQ) that appear five times in most mammalian species, a neurotoxic domain or central region (CR) (residues 106-126), and a hydrophobic domain (residues 112-135). Additionally, PrP harbours a disulphide bridge linking residues Cys-179 and Cys-214, and two glycosylation sites at residues Asn-181 and Asn197 (human $\operatorname{PrP}^{\mathrm{C}}$ numbering) (Refs 44, 45). Nuclear magnetic resonance spectroscopy analyses of fulllength recombinant murine and hamster $\mathrm{PrP}^{\mathrm{C}}$ indicate that the secondary structure of the protein consists of a globular domain (residues 126-226) containing three $\alpha$-helices, two $\beta$-strands, and a short helix-like segment comprising residues 222-226, a flexible random-coiled like N-terminal tail spanning residues 23-125, and a disordered C-terminal region (residues 227-231) (Refs 44, 46, 47).

The physiological role of $\operatorname{PrP}^{\mathrm{C}}$ is still under debate, and defining its cellular role is complicated by the lack of major anatomical or developmental defects observed in early studies with $\operatorname{PrP}^{\mathrm{C}}$-null $\left(\mathrm{PrP}^{-/-}\right)$ mice generated after germline genetic ablation of $\operatorname{PrP}^{\mathrm{C}}$ expression (Refs 48, 49). Likewise, $\operatorname{PrP}^{-/-}$ cattle produced by sequential gene-targeting showed 
no physiological, immunological and reproductive abnormalities (Ref. 50). Additionally, genetically engineered Prnp $^{+-}$and Prnp $^{-1-}$ goats (Refs 51, 52), and even those that are devoid of $\operatorname{PrP}^{\mathrm{C}}$ as a result of a naturally occurring nonsense mutation (Ref. 53), presented normal development and behaviour. Moreover, transgenic mice generated by cell-specific targeted cre-mediated post-natal ablation of $\operatorname{PrP}^{\mathrm{C}}$ in neurons, showed no evidence of neurodegeneration or other histopathological changes for up to 15 months postablation (Ref. 54). However, certain alterations in physiological functions were reported in some Prnp ${ }^{-1-}$ models. These included sleep disturbances, distorted circadian rhythm (Ref. 55), and abnormalities in synaptic transmission (specifically in cognition, olfactory physiology, and behaviour) [reviewed in (Refs 56, 57)]. Furthermore, one laboratory reported age-related defects in motor coordination and balance in $\mathrm{PrP}^{-/-}$mice; importantly, impaired mice displayed spongiform changes and reactive astrocytic gliosis in the brain, which usually accompany TSE pathology (Ref. 58). These findings suggested a plausible role for $\mathrm{PrP}^{\mathrm{C}}$ in neuroprotection during ageing. Electrophysiological studies pointed to a role for $\mathrm{PrP}^{\mathrm{C}}$ in modulating neuronal excitability. In these studies, $\mathrm{PrP}^{-/-}$mice exhibited long-term potentiation (LTP) impairment and reduced after-hyperpolarisation currents (Refs 59, 60). These findings were later confirmed in experiments involving post-natal removal of neuronal $\operatorname{PrP}^{\mathrm{C}}$ expression (Ref. 54).

The existing controversy in findings describing alterations in $\mathrm{PrP}^{-/-}$mice remains highly discussed, since variations in the genetic background of $\mathrm{PrP}^{-1-}$ mouse models and PrP-flanking genes, rather than $\operatorname{PrP}^{\mathrm{C}}$ absence, may account for some of the observed phenotypes (Refs 61, 62). Overall, what appears to be an irrefutable phenotype in $\mathrm{PrP}^{-1-}$ mice is resistance to infection with prions (Refs 63, 64, 65).

Many of the putative functions of $\operatorname{PrP}^{\mathrm{C}}$ are related to its cellular localisation. $\operatorname{PrP}^{\mathrm{C}}$ is attached to the outer leaflet of the plasma membrane through the GPI anchor (Ref. 43). In mammals, $\operatorname{PrP}^{\mathrm{C}}$ is expressed in various cell types throughout the body, with the highest levels reported in neurons (Refs 66, 67, 68, 69, $70,71,72$ ). While the exact $\operatorname{PrP}^{\mathrm{C}}$ localisation in the cell is still debated, three major sites have been identified: plasma membrane, Golgi apparatus and early and late endosomes (Ref. 73). $\operatorname{PrP}^{\mathrm{C}}$ is mainly localised in cholesterol-rich microdomains, or lipid-rafts, at the plasma membrane (Refs $73,74,75)$. Since lipid rafts are platforms for signal transduction processes, it has been suggested that $\operatorname{PrP}^{\mathrm{C}}$ may trigger signalling pathways inside the cell (Ref. 76), with the resulting modulation of neuronal survival (Refs 77, 78) or neuritic outgrowth (Refs 78, 79). Several groups localised $\mathrm{PrP}^{\mathrm{C}}$ at the membrane of synaptic specialisations, including pre- and post-synaptic membranes, and on synaptic vesicles (Refs 80, 81, 82, 83, 84), further supporting its proposed role in neuronal synaptic transmission regulation
(Refs 59, 60). Additionally, $\operatorname{PrP}^{\mathrm{C}}$ was shown to interact with several proteins involved in synaptic release (Refs 85, 86) and with various ion channels (Ref. 87). In line with these observations, PrP expression in Drosophila resulted in synaptic vesicle optimisation and higher vesicle release efficiency, supporting a functional role for $\operatorname{PrP}^{\mathrm{C}}$ in protein signalling and synaptic plasticity (Ref. 88).

In addition to its subcellular localisation, $\operatorname{PrP}^{\mathrm{C}}$ has been detected in the cytosol in certain subpopulations of neurons in the hippocampus, neocortex and thalamus, but not in the cerebellum (Ref. 80). These neurons may play a significant role in the pathogenesis of prion diseases (Refs 80, 89). Differences in cytosolic $\operatorname{PrP}^{\mathrm{C}}$ distribution have never been addressed, but it has been suggested that cytosolic $\operatorname{PrP}^{\mathrm{C}}$ may have altered propensity for aggregation. Additional studies revealed that mammalian cells contain all co-factors required for cytosolic prion propagation and dissemination (Ref. 90). Intriguing is the fact that, unlike mammals, the expression of $\operatorname{PrP}^{\mathrm{C}}$ in the CNS of adult chickens was observed in dendrites and axons of neurons associated with certain sensory systems, but not in neuronal bodies or glial cells (Ref. 91).

Recent studies highlight zebrafish as a useful model for studying proteins implicated in neurodegenerative diseases, including $\operatorname{PrP}^{\mathrm{C}}$ (Ref. 92). Zebrafish express high levels of duplicated PrP homologue proteins, namely PrP-1 and PrP-2, in the developing and adult brain (Refs 93, 94). Both proteins are functionally related and share similarities to mammalian $\operatorname{PrP}^{\mathrm{C}}$ in terms of domain composition, the presence of two Nglycosylation sites, and their binding to the plasma membrane via a GPI anchor (Refs 92, 94, 95, 96). However, unlike findings in mammals, genetic silencing of PrP-1 or PrP-2 caused profound morphological defects in zebrafish embryonal development, with the knocking down of each protein affecting different stages of embryogenesis. Further studies revealed a role for PrP-1 in cell-to-cell adhesion, not only through homophilic interactions, but also by modulating the E-cadherin signalling cascade and regulating cell-to-cell communication in vivo (Refs 92, 96). Moreover, interaction between Drosophila Schneider 2 cells separately expressing mouse and fish PrP resulted in cell aggregation and activation of an intracellular signalling cascade leading to the modulation of E-cadherin, suggesting that PrP trans-interactions are highly conserved and can take place across a wide range of species (Ref. 92).

Numerous putative neuroprotective functions attributed to $\operatorname{PrP}^{\mathrm{C}}$, including cell surface signalling, antioxidant and anti-apoptotic effects have been proposed [reviewed in (Ref. 97)]. Compelling evidence has been obtained for its role in myelination, autophagy regulation and trafficking of metal ions (Refs 98, 99, $100,101,102)$. Protein interaction analysis identified a subset of the ZIP (Zrt- Irt-like Protein) family of Zinc transporters as $\operatorname{PrP}^{\mathrm{C}}$ interaction partners. 
Additional sequence analysis across a wide range of species within the chordate lineage, suggested that the prion gene family is phylogenetically derived from a ZIP-like ancestral molecule, providing an explanation to the functional role of $\mathrm{PrP}^{\mathrm{C}}$ in the transmembrane transport of divalent cations (Ref. 103). $\mathrm{PrP}^{\mathrm{C}}$ is a copper $\left(\mathrm{Cu}^{2+}\right)$-binding protein that may play a role in $\mathrm{Cu}^{2+}$ homoeostasis by mediating $\mathrm{Cu}^{2+}$ transport or sequestration (Refs 104, 105). It has been debated whether binding of $\mathrm{Cu}^{2+}$ during PrP folding provides superoxide dismutase activity (SOD) on the protein (Refs 104, 106, 107) or if $\operatorname{PrP}^{\mathrm{C}}$ acts as an antioxidant by binding potentially harmful $\mathrm{Cu}^{2+}$ ions, quenching free radicals generated as a result of $\mathrm{Cu}^{2+}$ redox cycling (Ref. 108). A recent study performed with $\mathrm{PrP}^{\mathrm{C}}$-deficient neuronal cells, suggested $\mathrm{PrP}^{\mathrm{C}}$ participates in anti-apoptotic and anti-oxidative processes by interacting with the stress inducible protein 1 (STI-1) to regulate SOD activation, reconciling previously discordant findings (Ref. 109).

The $\operatorname{PrP}^{\mathrm{C}}$ octapeptide repeat region has limited structural similarity to the B-cell lymphoma 2 (Bcl-2) homology domain 2 (BH2) of the family of apoptosis regulating Bcl-2 proteins (Ref. 97). Binding studies performed with the yeast two-hybrid system demonstrated a direct interaction between $\operatorname{PrP}^{\mathrm{C}}$ and the C-terminus of anti-apoptotic Bcl-2, but not of pro-apoptotic Bcl-2-associated X protein (Bax) (Refs 110, 111). In light of these findings, it was proposed that $\mathrm{PrP}^{\mathrm{C}}$ might assume the neuroprotective function of $\mathrm{Bcl}-2$ proteins (Ref. 97). Indeed, hippocampal neurons isolated from $\mathrm{PrP}^{-1-}$ mice were more susceptible to serum deprivation-induced apoptosis than their wildtype counterparts, and overexpression of either $\operatorname{PrP}^{\mathrm{C}}$ or Bcl-2, rescued this phenotype (Ref. 112). Experiments with human primary neurons (Ref. 113) and yeast models expressing mammalian prions (Ref. 114) provided further support to the neuroprotective effect of $\operatorname{PrP}^{\mathrm{C}}$ in pro-apoptotic Bax-mediated cell death. Expression in primary neurons of mutant $\mathrm{PrP}^{\mathrm{C}}$ harbouring a four octapeptide repeat deletion or the pathogenic substitutions T183A or D178N implicated in familial forms of TSE (Ref. 113) fully or partially abolished $\mathrm{PrP}^{\mathrm{C}}$ neuroprotective function. Furthermore, Bax-mediated neuronal loss was reported in $\mathrm{Tg}(\mathrm{PG} 14)$ mice expressing, in analogy to a human mutation, $\operatorname{PrP}^{\mathrm{C}}$ with a nine extra octapeptide repeat insertion that perhaps lost its physiological function because of misfolding and/or protein aggregation (Ref. 115). The finding that GPI attachment is not required for $\operatorname{PrP}^{\mathrm{C}}$ cyto-protective function remains unexplained (Refs 113,114$)$. The role of $\operatorname{PrP}^{\mathrm{C}}$ in apoptosis will be further discussed.

The finding that $\mathrm{PrP}^{-/-}$mice show subtle abnormalities in immune system function, and that $\operatorname{PrP}^{\mathrm{C}}$ expression on bone marrow long-term hematopoietic stem cells seems to be important for self-renewal (Ref. 116), highlighted a physiological function for $\mathrm{PrP}^{\mathrm{C}}$ outside the CNS. $\operatorname{PrP}^{\mathrm{C}}$ was also implicated in
T-cell cytokine response, where Prnp mRNA up-regulation and increased $\mathrm{PrP}^{\mathrm{C}}$ expression followed $\mathrm{T}$-cell activation (Refs 117,118 ), while $\operatorname{PrP}^{\mathrm{C}}$ expression ablation led to reduced induction of helper T-cell cytokine production (Refs 118, 119). Additional studies, suggested a role for $\mathrm{PrP}^{\mathrm{C}}$ at the immunological synapse by showing that absence of $\operatorname{PrP}^{\mathrm{C}}$ on antigen presenting dendritic cells resulted in a significant reduction of proliferative potential of responding T-cells (Ref. 120).

\section{$\operatorname{PrP}^{C}$ interaction with proteins implicated in $A D$}

The membrane localisation of $\operatorname{PrP}^{\mathrm{C}}$ places this protein in close proximity with the amyloid precursor protein (APP) and other proteins involved in amyloid- $\beta$ (A $\beta$ ) processing. A putative role for $\operatorname{PrP}^{\mathrm{C}}$ in $\mathrm{AD}$ has been recently reviewed (Ref. 121).

In contrast to the earlier work presented by Parkin (Ref. 122) indicating a protective role for $\operatorname{PrP}^{\mathrm{C}}$, Lauren et al suggested that $\operatorname{PrP}^{\mathrm{C}}$ mediates oligomeric $\mathrm{A} \beta$ (oA $\beta$ ) neurotoxicity. One manifestation of this role is that $\operatorname{PrP}^{\mathrm{C}}$ is required for $\mathrm{oA} \beta$-induced LTP impairment (Ref. 123), a finding later confirmed by others (Ref. 124). Further studies provided evidence for the pathophysiological role of $\operatorname{PrP}^{\mathrm{C}}$ in mediating several other toxic effects of oA $\beta$, including synaptic plasticity disruption (Refs 124, 125), axonal degeneration of serotonergic neurons, synapse loss and deficits in spatial learning and memory (Ref. 126), neuronal cell death (Ref. 127) and synapse damage (Ref. 128). Alternative studies assert that $\operatorname{PrP}^{\mathrm{C}}$ is not required for A $\beta$-dependent synaptic depression, LTP impairment (Refs $129,130,131)$ or premature mortality, and abnormal neural network activity (Ref. 132). Others showed that, overexpression of $\operatorname{PrP}^{\mathrm{C}}$ prevents $\mathrm{A} \beta_{1-40}$-induced spatial learning and memory deficits by modulating programmed cell death pathways (Ref. 133).

$\mathrm{PrP}^{\mathrm{C}}$ may play a role in neurotoxic signalling pathways by sensitising cells to toxic effects of $\beta$-sheetrich conformers of different origins (Ref. 134). Other mechanisms have been described involving additional interacting molecules. One study showed that $A \beta$ neurotoxicity depends on interactions between $\mathrm{Cu}^{2+}$, $\mathrm{PrP}^{\mathrm{C}}$ and N-methyl-D-aspartate receptor (NMDA) (Ref. 135). Others revealed that neuronal impairment occurs via Fyn activation through oA $\beta$ binding to synaptic $\operatorname{PrP}^{\mathrm{C}}$ (Ref. 136).

While discrepancies in the contribution of $\operatorname{PrP}^{\mathrm{C}}$ to $\mathrm{AD}$ pathogenesis may have arisen from differences in the animal models and $A \beta$ preparations employed, all these studies suggest that the prion protein binds oA $\beta$. Further investigations will clarify the interrelationship of both proteins and neurodegeneration.

\section{Neurodegeneration pathways in prion disease}

Owing to the temporal and spatial coincidence of $\mathrm{PrP}^{\mathrm{TSE}}$ accumulation and the appearance of the first neurodegenerative changes in the brain, it has been suggested that either the loss of a critical biological 
function of $\operatorname{PrP}^{\mathrm{C}}$ or the acquisition of toxic properties upon conversion into $\mathrm{PrP}^{\mathrm{TSE}}$ triggers neurodegeneration and disease.

\section{Loss of $\operatorname{Pr} P^{C}$ function}

$\mathrm{PrP}^{\mathrm{C}}$ has been implicated in several mechanisms leading to neuronal protection from oxidative stress or other types of pro-apoptotic insults (Refs 97, 137). Therefore, it seems logical that conversion of $\mathrm{PrP}^{\mathrm{C}}$ into $\mathrm{PrP}^{\mathrm{TSE}}$ may render the former unable to perform its normal biological function, leading to neurodegeneration. This theory is strongly challenged, however, by compelling data showing normal embryonic development and absence of major anatomical or functional phenotypes in mammals where $\operatorname{PrP}^{\mathrm{C}}$ expression has been permanently or conditionally knocked out (Refs 48, 49, 50, 51, 52, 53, 54).

\section{Gain of toxic function}

$\mathrm{PrP}^{\mathrm{TSE}}$ is considered the surrogate marker of prion diseases. It accumulates in various regions of the brain, either in a diffused pattern or in the form of aggregates of different types depending on the strain of the agent and the host species (Refs 34,138). The co-occurrence of $\mathrm{PrP}^{\mathrm{TSE}}$ accumulation and spongiform changes in the brains of the majority of TSE patients, and in the brains of naturally and experimentally infected animals, prompted investigators to attribute a toxic function to $\operatorname{PrP}^{\mathrm{TSE}}$. This assumption was supported by in vitro studies reporting neurotoxicity of micromolar concentrations of short $\mathrm{PrP}^{\mathrm{C}}$ peptides, encompassing residues 106-126 of human $\operatorname{PrP}^{\mathrm{C}}$ (Ref. 139), and nanomolar concentrations of purified $\operatorname{PrP}^{\mathrm{TSE}}$ (Ref. 140).

While these data suggest a direct involvement of $\operatorname{PrP}^{\mathrm{TSE}}$ as the toxic agent in TSE pathogenesis, several lines of evidence do not support a causative relationship. Some forms of TSE, including FFI, have very restricted brain pathology with little or no spongiform change or detectable $\operatorname{PrP}^{\text {TSE }}$ (Ref. 141). PK-resistant $\operatorname{PrP}^{\mathrm{TSE}}$ has been identified in non-CJD brains suggesting that the accumulation of $\operatorname{PrP}^{\mathrm{TSE}}$ is probably not neurotoxic (Refs 142,143). Dissociation between $\mathrm{PrP}^{\mathrm{TSE}}$ and neurodegeneration has also been reported in several cases of natural and experimental human prion disease, where neuropathological changes occurred in the absence or with very limited $\mathrm{PrP}^{\mathrm{TSE}}$ accumulation (Refs 144, 145, 146, 147). A number of studies have reported no correlation between $\operatorname{PrP}^{\mathrm{TSE}}$ deposition and neurodegeneration in the brains of infected mice expressing half the normal levels of $\operatorname{PrP}^{\mathrm{C}}$ (Refs 148, 149, 150, 151). Bueler and colleagues showed that although these mice accumulated PrP ${ }^{\text {TSE }}$ and infectivity titres similar to those found in clinically sick, wild-type animals, they had a significant delay in disease onset and progression indicative of relative resistance to the toxic effects of prions (Ref. 150). Likewise, it is well documented the existence of subclinical carriers of prion infection, with wild-type mice living a typical lifespan despite harboring
$\operatorname{PrP}^{\mathrm{TSE}}$ titers similar to mice at the end-stage of the disease (Refs 152, 153, 154, 155, 156, 157). Compelling experimental evidence against the direct neurotoxic effect of $\operatorname{PrP}^{\mathrm{TSE}}$ was first obtained in the seminal studies by Aguzzi and colleagues (Refs 158, 159) who showed that intra-cerebral injection of prions in $\mathrm{PrP}^{\mathrm{C}}$-null mice with grafted neural tissue from a mouse overexpressing $\operatorname{PrP}^{\mathrm{C}}$, resulted in severe spongiform changes, infectivity, and PK-resistant $\mathrm{PrP}^{\mathrm{TSE}}$ in the grafts. However, while in some instances $\operatorname{PrP}^{\mathrm{TSE}}$ was found in brain areas outside the graft, these regions were spared from neurodegenerative changes (Refs 158, 159). Work by Mallucci et al. (Ref. 160) provided additional proof against a direct role of $\mathrm{PrP}^{\mathrm{TSE}}$ in neurotoxicity. By specifically knocking down $\operatorname{PrP}^{\mathrm{C}}$ expression in mouse neurons after established prion neuroinvasion, they showed reversion of early spongiform changes and prevention of disease progression, despite continuous accumulation of $\mathrm{PrP}^{\mathrm{TSE}}$ in the neuropil (the latter coming from the conversion of $\operatorname{PrP}^{\mathrm{C}}$ produced in nonneuronal cells) (Ref. 160).

Multiple studies suggested that soluble oligomeric species, intermediates in the formation of proteaseresistant $\operatorname{Pr} \mathrm{P}^{\mathrm{TSE}}$, are the pathogenic entity rather than insoluble $\operatorname{PrP}^{\mathrm{TSE}}$ aggregates (Refs 161, 162, 163, $164,165,166)$. The idea has been further developed that $\operatorname{PrP}^{\mathrm{TSE}}$ replication and neurotoxicity occur in two separate phases, where the production of a neurotoxic species $\left(\operatorname{PrP}^{\mathrm{L}}\right)$ is catalysed by $\operatorname{PrP}^{\mathrm{TSE}}$. According to this model, when $\operatorname{PrP}^{\mathrm{TSE}}$ amplification saturates, the autocatalytic production of infectivity (phase 1) switches into a toxic pathway (phase 2) leading to the formation of toxic PrP species. Importantly, the formation of $\operatorname{PrP}^{\mathrm{L}}$ is linearly dependent on $\operatorname{PrP}^{\mathrm{C}}$ concentration (Refs 34, 148, 151).

\section{Subversion of $\operatorname{Pr} P^{C}$ function}

The experimental observation that $\operatorname{PrP}^{\mathrm{C}}$ expression at the neuronal membrane is required to transduce a toxic signal inside the cell (Refs 54, 167) established the molecular basis of a new mechanism to explain neurotoxicity in prion diseases: subversion of $\operatorname{PrP}^{\mathrm{C}}$ function (Ref. 168), whereby interaction between $\operatorname{PrP}^{\mathrm{C}}$ and $\mathrm{PrP}^{\mathrm{TSE}}$, or intermediate species, subverts or modifies the normal function of $\operatorname{PrP}^{\mathrm{C}}$, triggering a toxic signal inside the cell (Fig. 2). While the prevailing data argue for the necessity of neuronal $\mathrm{PrP}^{\mathrm{C}}$ expression for neurotoxicity, some challenging evidence still exists (Refs 54, 149, 165, 166, 167, 169, 170). Studies by Zhou et al. identified a monomeric, highly $a$-helical form of $\operatorname{PrP}^{\mathrm{C}}$, the so-called toxic $\operatorname{PrP}$ (TPrP), as the most neurotoxic PrP species in vitro and in vivo. TPrP was generated in vitro by size fractionation following dilution refolding of full-length mouse recombinant $\operatorname{PrP}^{\mathrm{C}}$, and it was shown to elicit autophagy, apoptosis and a molecular signature similar to that observed in the brains of prion-infected animals (Ref. 170). TPrP was toxic to $\mathrm{PrP}^{-/-}$mouse- 


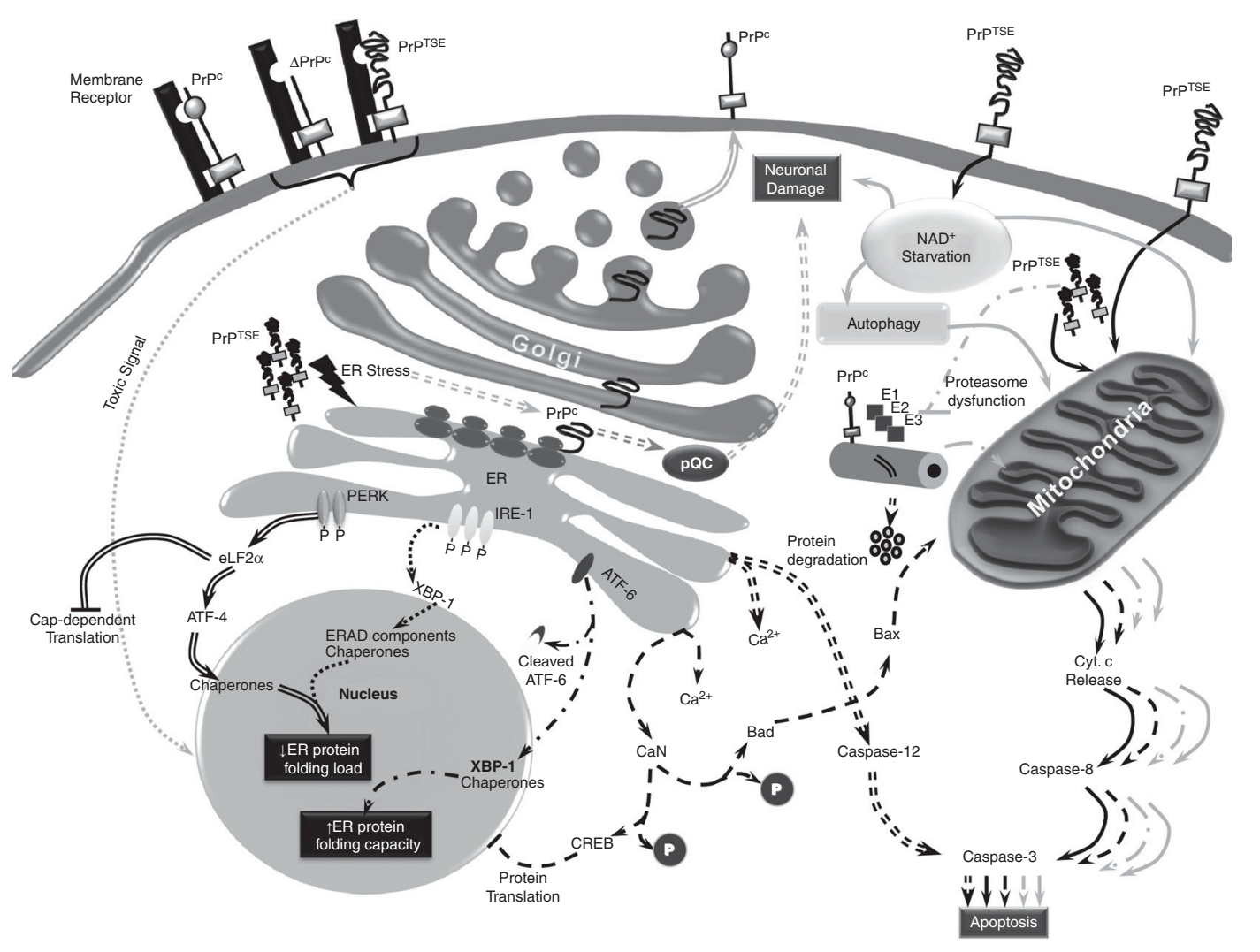

\section{Putative molecular mechanisms of prion-induced neurodegeneration}

Expert Reviews in Molecular Medicine (C) 2016 Cambridge University Press

FIGURE 2

Putative molecular mechanisms of prion-induced neurodegeneration. Schematic representation of different mechanisms by which $\operatorname{Pr} \mathrm{P}^{\mathrm{C}}$ misfolding and $\mathrm{PrP}^{\mathrm{TSE}}$ accumulation may result in cellular death and neuronal damage. $\mathrm{PrP}^{\mathrm{C}}$ synthesis: solid grey double lines. Subversion of function/ Excitotoxic stress: dotted grey line. The mitochondrial pathway of apoptosis: solid black line. Endoplasmic reticulum stress-induced apoptosis: dotted black double lines. Endoplasmic reticulum stress: dashed black line. The preemptive quality control (pQC) pathway: dotted grey double lines. The unfolded protein response, IRE-1 arm: dotted black line. The unfolded protein response, PERK arm: solid black double lines. The unfolded protein response, ATF-6 arm: dash-dotted black line. The ubiquitin-proteasome system (UPS) and the aggresome: dash-dotted grey line. Normal $\mathrm{PrP}^{\mathrm{C}}$ degradation by the proteasome: dash-dotted black double lines. $\mathrm{NAD}^{+}$starvation: solid grey line. Cyt. C: Cytochrome C, E1: Ubiquitin activating enzyme, E2: Ubiquitin conjugating enzyme, E3: Ubiquitin protein ligase. $\rightarrow$ Activates route.

derived hippocampal neurons in vitro, supporting the hypothesis that endogenous neuronal $\operatorname{PrP}^{\mathrm{C}}$ is not required to propagate a toxic signal inside the cell (Ref. 170). However, even if TPrP toxicity does not rely on membrane-bound $\operatorname{PrP}^{\mathrm{C}}$ expression, experimental evidence suggests that it should be generated within neurons, given that post-natal ablation of $\operatorname{PrP}^{\mathrm{C}}$ expression in these cells reverses early neurodegenerative changes and prevents disease progression in mice, even though glial replication and accumulation of $\operatorname{PrP}^{\mathrm{TSE}}$ continues (Ref. 54). Indeed, growing evidence indicates that prion-induced pathology comprises cellautonomous mechanisms, resulting in cellular dysfunction and neurodegeneration, and noncell-autonomous processes leading to prion spread (Ref. 171).

Studies performed with $\mathrm{Tg} 44$ transgenic mice expressing $\operatorname{PrP}^{\mathrm{C}}$ that lacks the GPI membrane anchoring signal $\left(\mathrm{GPI}^{-}-\mathrm{PrP}^{\mathrm{C}}\right)$ provided additional supporting evidence to the dissociation between prion replication and neurotoxicity (Refs 149, 169, 172). In anchorless-PrP ${ }^{\mathrm{C}}$ transgenic mice, about $90 \%$ of $\mathrm{GPI}^{-}-\mathrm{PrP}^{\mathrm{C}}$ is secreted, the rest appearing in the ER and Golgi complex, but not on the plasma membrane. Scrapie infection of Tg44 mice resulted in a substantially different disease than that observed in wild-type mice, with an incubation period, clinical signs and neuropathological abnormalities characteristic of cerebral amyloid angiopathy (CAA) (Refs 149, 169, 173). Spongiform grey matter degeneration was minimal or not present in the brains of diseased mice, and this feature was preserved through subsequent multiple passages in $\mathrm{Tg} 44$. However, the brains of these mice contained large deposits of amyloid $\operatorname{PrP}^{\mathrm{TSE}}$ and high levels of infectivity that caused classical grey matter 
spongiosis with $\operatorname{PrP}^{\mathrm{TSE}}$ accumulation in wild-type mice (Ref. 169). Experimental studies involving peripheral scrapie infection of $\operatorname{Tg} 44$ mice revealed a crucial role for membrane-bound $\operatorname{PrP}^{\mathrm{C}}$ in neuroinvasion and neuronal $\mathrm{PrP}^{\mathrm{TSE}}$ spread (Ref. 173), and for the induction of a typical TSE pathogenic process (Ref. 149). Interestingly, whereas the neuropathogenic processes found in Tg44 mice i.c. injected with prions were distinct from typical prion disease, they were reminiscent of changes found in familial forms of TSEs associated with STOP mutations at codons 145, 163 and 226 of PRNP (Refs 174, 175, 176). These changes involved dense amyloid $\mathrm{PrP}^{\mathrm{TSE}}$ plaque deposits with $\mathrm{CAA}$, but without grey matter spongiosis.

Because prion diseases are a group of diverse disorders characterised by different disease phenotypes and different pathological features (Ref. 177), it is likely that neuropathogenesis in these disorders is triggered by different mechanisms, the majority of which depend on $\operatorname{PrP}^{\mathrm{C}}$ anchoring to the neuronal membrane. In typical prion disease, neuronal $\operatorname{PrP}^{\mathrm{C}}$ is required for neuroinvasion and for $\mathrm{PrP}^{\mathrm{TSE}}$-mediated neurotoxic membrane interactions (Ref. 149). Neurotoxicity independent of neuronal $\operatorname{PrP}^{\mathrm{C}}$ expression was observed in $\mathrm{Tg} 44$ mice after i.c. injection of scrapie, where neuropathogenesis was likely the result of tissue distortion by amyloid plaques, obstruction of interstitial fluid flow, and vascular occlusion triggered by the accumulation of $\operatorname{PrP}^{\mathrm{TSE}}$ amyloid within basement membranes and interstitial space between neurite and glial processes. Proteomic analysis of CAA and nonamyloid TSE disease phenotypes in mice revealed similarities and differences in the mechanism of pathogenesis (Ref. 178). Following scrapie infection with the scrapie strain RML, the brains of wild-type and Tg44 mice showed evidence of a neuroinflammatory response and complement activation. However, ERassociated degradation (ERAD) and mitochondrial induced apoptosis pathways were implicated only in wild-type animals exhibiting nonamyloid disease phenotype, whereas metal binding and synaptic vesicle transport were more profoundly disrupted in $\mathrm{Tg} 44$ mice with $\mathrm{PrP}^{\mathrm{TSE}}$-CAA accumulation (Ref. 178). A similar unique mechanism may be responsible for the phenotypic differences observed in certain forms of human TSE (Ref. 149).

\section{Molecular and cellular mechanisms of neuronal death}

With just few exceptions, TSEs are characterised at the neuropathological level by various degrees of spongiform vacuolation of the neuropil, accompanied by neuronal cell loss and gliosis, which together constitute the classic neuropathological triad of TSEs (Ref. 42). Ultrastructural studies revealed that typical 'spongiform vacuoles' develop within neuronal elements or within myelinated axons or myelin sheaths. The origin of these vacuoles is still debated, but the prevailing view attributes their occurrence to autophagy rather than to abnormalities in membrane permeability leading to increased water retention (Refs 137, 179).

\section{Autophagy in prion diseases}

Basal autophagy plays an important role in maintaining cell homeostasis and physiological function. It is characterised by the formation of cytoplasmic autophagic vacuoles that fuse with lysosomes to degrade and recycle the vesicular content. This is a tissue-specific, tightly regulated process mediated via the lysosomal degradation pathway. Alternatively, autophagy induced by various cellular insults is recognised as one of the three mechanisms of programmed cell death in eukaryotes (Ref. 180).

Autophagic vacuoles have been identified in several neurodegenerative diseases, including various forms of TSEs (Refs 181, 182, 183). Since, under normal conditions, autophagy takes place at low levels in the CNS an increase in the number of autophagosomes in prioninfected brains was interpreted by some as cause of neurodegeneration (Refs 170, 184, 185). However, based on recent studies providing evidence that $\mathrm{PrP}^{\mathrm{C}}$ may play a role in autophagy regulation in neurons, and since the absence of $\operatorname{PrP}^{\mathrm{C}}$ expression resulted in autophagy up-regulation (Ref. 102), it can be argued that loss or subversion of $\operatorname{PrP}^{\mathrm{C}}$ function during prion infection may trigger a similar response.

Although some authors consider autophagosomes to be part of the mechanism leading to neuronal death (Refs 170,184), a debate continues as to whether they play a neuroprotective role through degradation of intraneuronal deposits of $\mathrm{PrP}^{\mathrm{TSE}}$. Early studies showed impaired $\mathrm{PrP}^{\mathrm{TSE}}$ aggregation and protection against oxidative damage following trehalose treatment of prion-infected cells (Ref. 186). Schatzl and colleagues advanced these observations and provided direct in vitro evidence of autophagy-induced $\operatorname{PrP}^{\mathrm{TSE}}$ degradation (Ref. 181). Pharmacological treatment of prioninfected neuronal and non-neuronal cells, with the autophagy-inducing agents imatinib, rapamycin, lithium and trehalose, increased cellular clearance of $\operatorname{PrP}^{\text {TSE }}$ (Refs 187, 188, 189). Early administration of imatinib after peripheral inoculation of prions in mice delayed disease onset and accumulation of $\operatorname{PrP}^{\mathrm{TSE}}$ in the CNS (Ref. 190). However, neither intraperitoneal nor intracerebroventricular delivery of the drug showed beneficial effect on $\operatorname{PrP}^{\mathrm{TSE}}$ clearance in the CNS (Ref. 190). Likewise, the survival of mice i.p. infected with scrapie was not influenced by trehalose treatment despite the delayed appearance of $\operatorname{PrP}^{\mathrm{TSE}}$ in the spleen (Ref. 187).

Recent observations derived from the pharmacological manipulation of autophagy with either autophagy-enhancing or -inhibiting drugs showing no changes on the time course or amplitude of neuronal death in response to TPrP exposure, strongly suggested that the observed autophagy in protein misfolding diseases is a secondary mechanism in the neurodegenerative process (Ref. 191). Consistent with this idea are in 
vivo studies where $\operatorname{Tg}(\mathrm{PrP}-\mathrm{A} 116 \mathrm{~V})$ mice, a model of GSS, were chronically treated with i.p. injections of rapamycin. Drug treatment led to a dose-dependent delay in disease onset, a reduction in symptom severity, and improved survival concomitant with increased levels of the autophagy-specific marker LC3-II (microtubule-associated protein 1A/1B-light chain 3-phosphatidylethanolamine conjugate), reduced levels of insoluble PrP-A116V, and a near to complete absence of PrP amyloid plaques in the brain. However, despite the reported reduction in amyloid burden, these mice eventually reached terminal levels of motor impairment and succumbed to the disease (Ref. 192).

\section{Role of apoptosis in TSEs}

Not all histopathological changes identified in TSEaffected brains can be attributed to the activation of cellular autophagy. Indeed, several studies conducted in natural disease and experimental models of TSEs observed DNA fragmentation and the activation of several caspases, indicating that neuronal death may occur via apoptotic pathways (Refs 193, 194, 195).

The mitochondrial pathway. This was identified in experimental models where aggregated PrP peptides, like PrP106-126, or recombinant mutant PrP were used (Refs 196, 197, 198). These toxic forms of PrP caused alterations in the mitochondrial membrane leading to mitochondrial stress, cytochrome c release, caspase activation, and ultimately, neuronal death (Fig. 2, solid black line). Early findings suggested that cerebellar granule neurons (CGNs) in $\mathrm{Tg}(\mathrm{PG} 14)$ mice died via a Bax-dependent process (Refs 115, 199). However, crossing these animals with $\mathrm{Bax}^{-1-}$ mice had no effect on disease onset and duration. Additionally, despite Bax inactivation significantly inhibited apoptotic death of CGNs, it did not rescue synaptic degeneration and did not prevent neurological disease. Instead, these findings supported synaptic degeneration, and not apoptotic neuronal loss, as the primary pathologic event contributing to the clinical signs observed in this model (Ref. 115). Experiments with Bax deficient mice provided additional evidence against the primary role of proapoptotic Bax in neuronal cell death. Inoculation of $\mathrm{Bax}^{-/-}$and wild-type control mice with mouse-adapted BSE prions showed no differences in terms of $\operatorname{PrP}^{\mathrm{TSE}}$ accumulation, neurodegeneration, disease onset and clinical signs, providing compelling evidence that Bax-mediated cell death was not involved in the pathological mechanism induced by BSE (Ref. 200). Nevertheless, cleaved caspase-3 and -9 were found in the brains of $\mathrm{Bax}^{-1-}$ mice, suggesting that apoptosis may occur through an alternative mechanism in TSEs of infectious origin. These observations were consistent with previous findings of apoptotic features in the brains of wild-type mice infected with RML, in the absence of Bax upregulation (Ref. 201). More recently, proteomic analyses of wild-type mice injected with the same agent revealed upregulation of proteins involved in cell death and survival; in particular, in the levels of proteins associated with the mitochondrial inner membrane, proteins associated with the ubiquitin/proteasome pathway, and proteins involved in the ERAD (Ref. 178), but not in the brains of RML-infected Tg44 mice. This evidence further supported the notion that distinct pathways may be activated in TSEs of different aetiology.

The endoplasmic reticulum pathway. ER stress has been recently discovered as a novel apoptotic-regulatory pathway, with implications in $\beta$-amyloid cytotoxicity (Ref. 202). Stress of the ER results from changes in $\mathrm{Ca}^{2+}$ homoeostasis or accumulation of aggregated proteins. Either situation will induce $\mathrm{Ca}^{2+}$ release from the ER and activation of the ER-membrane-resident caspase-12. Following activation, caspase-12 is released into the cytoplasm where it activates downstream caspases of the apoptotic response (Fig. 2, dotted black double lines). Additionally, $\mathrm{Ca}^{2+}$ regulates calcineurin $(\mathrm{CaN})$, a type 2 phosphatase involved in synaptic function, memory and cell death (Ref. 203).

Dysregulation of intracellular $\mathrm{Ca}^{2+}$ balance has been described in a number of neurodegenerative proteinopathies, including TSEs (Ref. 140). Early studies identified ER stress and caspase-12 activation in murine neuroblastoma (N2a) cells infected with highly purified prion preparations. Similar changes were observed in prion-infected mice as well as in brains of patients affected with vCJD and sCJD (Ref. 140). But, even if these findings initially suggested the involvement of a caspase-12-dependent apoptotic pathway in naturally occurring prion diseases, infectivity studies with caspase- 12 knockout and wild-type mice revealed identical disease onset and progression, irrespective of caspase-12 expression, arguing against its role in neurotoxicity (Ref. 204).

Further investigations on the role of ER stress and $\mathrm{Ca}^{2+}$ homoeostasis in neurodegeneration suggested that $\operatorname{PrP}^{\mathrm{TSE}}$ accumulation caused synaptic dysfunction and neuronal death via $\mathrm{CaN}$ activity dysregulation (Ref. 205). This hypothesis stemmed from in vitro studies with N2a cells that were either treated with brain-derived $\operatorname{PrP}^{\mathrm{TSE}}$, or engineered to overexpress mutant PrP forms associated with familial TSEs. Thus, pharmacological manipulation of $\mathrm{Ca}^{2+}$ homoeostasis in scrapie-infected N2a cells led to ER stress (Ref. 206). Moreover, treatment of cells with brain-derived $\operatorname{PrP}^{\mathrm{TSE}}$ induced upregulation of the unfolded protein response (UPR)-responsive chaperones glucose regulated protein (Grp) 58, Grp78, and Grp94, which was indicative of ER stress. Additionally, overexpression of SERCA (ER-Ca ${ }^{2+}$ ATPase) in cells made them highly susceptible to $\mathrm{PrP}^{\mathrm{TSE}}$-induced cell death. The study of N2a cells overexpressing murine $\operatorname{PrP}$ carrying mutations associated with FFI $\left(\mathrm{PrP}^{\mathrm{D} 177 \mathrm{~N} / \mathrm{Met128}}\right)$ (murine PrP numbering) or GSS $\left(\mathrm{PrP}^{\mathrm{PG} 14}\right)$, or neurotoxic transmembrane 
forms, showed decreased ER $\mathrm{Ca}^{2+}$ content upon treatment with $\mathrm{Ca}^{2+}$ agonists (Ref. 206). According to this model, hyperactivation of $\mathrm{CaN}$, because of increased cytosolic levels of $\mathrm{Ca}^{2+}$, results in the dysregulation of the pro-apoptotic molecule Bcl-2-associated death promoter $(\mathrm{Bad})$, and the transcription factor cAMP response element-binding (CREB), among other targets. Upon dephosphorylation, Bad interacts with Bax causing mitochondrial stress and apoptosis. Dephosphorylated CREB cannot translocate into the nucleus, where it regulates the transcription of proteins involved in synaptic plasticity, resulting in synaptic degeneration (Ref. 207) (Fig. 2, dashed black line). Consistently, disruption in the expression of proteins involved in $\mathrm{Ca}^{2+}$ homoeostasis and synaptic vesicle transport were also found in Tg44 mice with CAA (Ref. 178).

\section{Other mechanisms of neurodegeneration}

The studies described above suggest that autophagy and apoptosis are rather a secondary consequence of prion-induced neurodegeneration. To better understand the mechanism behind this process many laboratories have hypothesised alternative pathways triggering neurodegeneration based on other pathophysiological changes observed in the cell.

Excitotoxic stress. Important information about $\mathrm{PrP}^{\mathrm{C}}$ function and prion neurotoxicity has been gathered from the analysis of phenotypic variations produced by several $\operatorname{PrP}^{\mathrm{C}}$ deletion mutants in transgenic mice. It has been repeatedly shown that deletions within the $\mathrm{N}$-terminal half of $\operatorname{PrP}^{\mathrm{C}}$ cause massive neuronal death in transgenic mice (Refs 208, 209, 210). This phenotype was rescued in a dose-dependent manner by coexpression of full-length $\operatorname{PrP}^{\mathrm{C}}$. Therefore, it has been suggested that wild-type and truncated $\mathrm{PrP}^{\mathrm{C}}$ bind to a common molecular target eliciting two different responses in the cell: while truncated- $\operatorname{PrP}^{\mathrm{C}}$ binding triggers a toxic signal, binding of wild-type $\mathrm{PrP}^{\mathrm{C}}$ restores a nontoxic physiological function (Ref. 211) (Fig. 2, dotted grey line).

Transgenic mice expressing $\operatorname{PrP}^{\mathrm{C}}$ harbouring a deletion within the highly conserved $\mathrm{CR}$ of the protein, residues 105-125 (PrP $\Delta \mathrm{CR}$ ) (murine PrP numbering), have been generated in an attempt to define the $\operatorname{PrP}^{\mathrm{C}}$ sequence determining neurotoxicity (Ref. 209). When $\operatorname{PrP} \triangle \mathrm{CR}$ was expressed on the Prnp ${ }^{-1-}$ background, mice died within the first week of life, whereas coexpression of wild-type $\mathrm{PrP}^{\mathrm{C}}$ alleviated the phenotype in a dose-dependent fashion. Neuropathological examination of mice co-expressing $\operatorname{PrP} \Delta \mathrm{CR}$ and one Prnp allele revealed dramatic degeneration of CGNs and vacuolation of white matter regions, features observed in TSEs (Ref. 212). Biochemical and morphological analyses could not attribute CGN death to apoptosis or autophagy, since no activation of caspases 3 or 8 , or increased levels of the autophagy marker LC3-II were detected in these animals. Instead, degenerating
CGNs displayed a cytoplasmic morphology reminiscent of certain forms of excitotoxic neuronal death characterised by heterogeneous condensation of the nuclear matrix without formation of discrete chromatin masses (Ref. 212). The same morphology was present in the neurons of transgenic mice expressing a different deletion mutant, $\operatorname{PrP} \Delta 32-134$. These findings suggested common neurotoxic mechanisms for $\mathrm{PrP}^{\mathrm{C}}$ proteins missing the CR (Ref. 212) (Fig. 2).

The preemptive quality control ( $p Q C$ ) system. To further explain the necessity of a continuous supply of $\mathrm{PrP}^{\mathrm{C}}$ for neurotoxicity, Rane and colleagues, advancing an original idea by Orsi et al. (Ref. 213), proposed that the alteration of the cellular metabolism resulted in the synthesis of a neurotoxic form of $\operatorname{PrP}^{\mathrm{C}}$ (Ref. 214). Given the implication of this pathway in $\operatorname{PrP}^{\mathrm{TSE}}$ pathogenesis (Ref. 140), the authors highlighted chronic ER stress as an example of altered cellular metabolism, and suggested the existence and involvement of the pQC pathway (Refs 214, 215).

There are three mechanisms by which proteins may be degraded in the cytosol: failed targeting, retrotranslocation and pQC. However, only the pQC pathway is activated under ER stress. There is no evidence that $\operatorname{PrP}^{\mathrm{C}}$ is synthesised in the cytosol or is retrotranslocated from the ER during normal and stress conditions (Ref. 216). In light of these data, it has been suggested that $\operatorname{PrP}^{\mathrm{TSE}}$ accumulation triggers ER stress. Consequently, $\operatorname{PrP}^{\mathrm{C}}$ is no longer translocated into the ER but rapidly degraded by the $\mathrm{pQC}$ pathway. Persistent, accelerated routing of $\operatorname{PrP}^{\mathrm{C}}$ through the pQC results in neuronal damage and corresponding clinical symptoms by an unknown mechanism (Ref. 214) (Fig. 2, dotted grey double lines).

Since the model did not fully recapitulate all clinical and histopathological changes found in prion diseases, it was proposed that several pathways lead to neurodegeneration in these disorders, including increased production of transmembrane forms of $\operatorname{PrP}\left({ }^{\mathrm{Ctm}} \mathrm{PrP}\right)$, decreased proteasome activity, or generation of a toxic intermediate during prion conversion (Ref. 214).

The UPR. UPR activation is a cellular response to reestablish homeostasis by synthesis of properly folded proteins. It affects the expression of chaperones, enhances degradation of unfolded and mutated proteins, and inhibits protein synthesis (Ref. 217). When the concentration of unfolded proteins in the lumen reaches a threshold, a set of intracellular signal transduction pathways involving three transmembrane ERresident signalling components, namely inositol requiring enzyme 1 (IRE1), activating transcription factor 6 (ATF6) and double-stranded RNA-activated protein kinase (PKR)-like ER kinase (PERK), is activated. Prolonged activity of the UPR is indicative of chronic ER stress and results in cellular apoptosis (Refs 217, 218). 
IRE1, a bifunctional transmembrane kinase-endoribonuclease protein, initiates the nonconventional splicing of mRNA to propagate the UPR signal (Refs 217, 219). Activated IRE1 facilitates generation of an active form of the X-box binding protein 1 (XBP-1), a UPR-specific transcription factor that enhances the transcription of UPR genes involved in protein quality control, and activates ERAD among other targets (Ref. 220) (Fig. 2 dotted black line). While early in vitro studies in N2a cells indicated a protective role for UPR activation against $\mathrm{PrP}^{\mathrm{C}}$ misfolding under ER stress mediated by XBP-1 (Ref. 219), infection of conditional XBP-1 knockout mice with prions demonstrated that ablation of this gene had no effect on neuronal function and prion pathogenesis in vivo, providing compelling evidence against the hypothesised neuroprotective role of the XBP-1 branch of the UPR (Ref. 221).

Later studies in $\mathrm{PrP}^{\mathrm{C}}$ overexpressing Tg37 MloxP transgenic mice explored the involvement of the arm of the UPR responsible for translational control. This mechanism is directed by PERK phosphorylation of the ubiquitous eukaryotic translation initiation factor 2 (eIF2 $\alpha$ ) (Fig. 2, solid black double lines) (Ref. 222). Upon ER stress, PERK aggregates and phosphorylates itself and eIF2 $\alpha$ (PERK-P and eIF2 $\alpha-$ $P)$. Phosphorylation inactivates eIF $2 \alpha$, and inhibits mRNA translation, therefore reducing the protein load in the ER to alleviate ER-stress (Ref. 217). However, sustained elevation of eIF2 $\alpha-P$ leads to a decline in global translation rates and loss of synaptic proteins, contributing to neuronal death. Importantly, increased levels of PERK-P and eIF2 $\alpha-P$ were detected throughout the course of the disease in RML-infected Tg37 mice (Ref. 222). Reduction of eIF2 $\alpha-P$ levels by lentiviral-induced overexpression of GADD34, an eIF2 $\alpha-\mathrm{P}-$ specific phosphatase, or inhibition of $\operatorname{PrP}^{\mathrm{C}}$ expression by anti-PrP shRNA, rescued the pathologic phenotype and significantly increased mouse survival (Ref. 222). In contrast, pharmacological inhibition of eIF2 $\alpha-P$ dephosphorylation further enhanced neurotoxicity and significantly accelerated the disease (Ref. 222). These data strongly supported the conclusion that chronic UPR stress, with persistent expression of eIF $2 \alpha-P$ and continuing inhibition of protein synthesis, leads to synaptic failure, spongiosis and neuronal loss in TSEs (Ref. 222).

The ubiquitin-proteasome system (UPS) and the aggresome. Ubiquitination is an efficient system for targeting cellular proteins for degradation. However, impairment of the proteasomal machinery can result in atypical ubiquitination of proteins and accumulation of ubiquitinated proteasomal substrates. Aberrations in the regulation of the UPS have been associated with a wide range of neurodegenerative diseases (Refs 223, 224). The $26 \mathrm{~S}$ proteasomal complex comprises a $20 \mathrm{~S}$ proteolytic core complexed at one or both ends with a $19 \mathrm{~S}$ regulatory complex. The $20 \mathrm{~S}$ proteasome is composed of $14 \alpha$ and $14 \beta$ subunits arranged in four stacked rings, the two outer rings consisting of $7 \alpha$ units and the two inner rings of $7 \beta$ subunits each. This organisation gives the 20S proteasome the appearance of a hollow barrel. Under physiological conditions, a small fraction of $\operatorname{PrP}^{\mathrm{C}}$ undergoes ubiquitination and proteasomal degradation (Ref. 225). Positive ubiquitin staining of proteins was found in brains of CJD patients and experimental scrapie-infected mice (Refs 226, 227). In humans afflicted with CJD, extensive aggregated deposits of $\mathrm{PrP}^{\mathrm{TSE}}$ frequently co-localise with ubiquitin, while fine granular deposits do not appear to be ubiquitinated (Ref. 228). The notion that in scrapie-infected mice protein ubiquitination increased during infection while proteasomal activity declined, led to the suggestion that ubiquitination occurs after the formation of protease-resistant $\operatorname{PrP}^{\mathrm{TSE}}$ (Ref. 229) (Fig. 2, dash-dotted grey line). Studies using scrapie-infected N2a cells showed that $\mathrm{PrP}^{\mathrm{TSE}}$ co-localised with the cytosolic marker heat shock cognate protein 70 (Hsc70) (Refs 230, 231) and that mild proteasome inhibition led to $\operatorname{PrP}^{\mathrm{TSE}}$ accumulation in the form of large cytoplasmic perinuclear aggresomes (Ref. 230). In the aggresome, $\mathrm{PrP}^{\mathrm{TSE}}$ co-localised with $20 \mathrm{~S}$ proteasome and ubiquitin, and $\mathrm{PrP}^{\mathrm{TSE}}$ aggresome formation was associated with caspase- 8 and -3 activation and apoptosis (Ref. 230), hence confirming previous evidence suggesting caspase- 3 activation in affected brain areas of scrapie-infected mice (Refs 201, 232). Later studies provided strong evidence that accumulation of $\mathrm{PrP}^{\mathrm{TSE}}$ in the cytosol inhibits the UPS, and partially explained the molecular mechanisms behind this inhibition. Thus, in N2a cells stably expressing the fluorogenic proteasome reporter substrate $\mathrm{Ub}^{\mathrm{G} 76 \mathrm{~V}}-\mathrm{GFP}$, scrapie infection led to increased levels of the reporter protein, while curing cells of infection with the anti-PrP monoclonal antibody ICMS18 normalised substrate degradation (Ref. 231). Aggregated $\beta$-sheet rich PrP $(\beta-\operatorname{PrP})$ and small $\operatorname{PrP}^{\mathrm{TSE}}$ oligomers specifically inhibited the proteolytic activities, namely chymotrypsin-like and caspase-like activities, of the $26 \mathrm{~S}$ proteasome beta subunits as a result of decreased gate opening of the $20 \mathrm{~S}$ particle, but not via dissociation of the 26S proteasome (Ref. 231). Supporting evidence was obtained in vivo with transgenic mice expressing the $\mathrm{Ub}^{\mathrm{G} 76 \mathrm{~V}}$-GFP reporter protein. These mice displayed diminished capacity to degrade the reporter protein, which accumulated as aggregated deposits in the cytosol of neurons in the most affected brain regions during scrapie infection (Ref. 231). Importantly, the recent identification of changes in the relative levels of heat shock protein HSPA5 and chaperonin TCP1 in mice infected with RML, is consistent with the involvement of the UPS in prion neurodegeneration (Ref. 178).

In sharp contrast are findings in mouse models of inherited prion disorders (Ref. 233). Double-Tg mice, co-expressing PrP with a nine-octapeptide-repeat insertional mutation (PG14) and the $\mathrm{Ub}^{\mathrm{G} 76 \mathrm{~V}}$-GFP reporter, displayed no evidence of UPS impairment despite 
showing cytosolic PrP accumulation. Pharmacological induction of cytosolic PrP accumulation in hippocampal neurons from $\mathrm{Ub}^{\mathrm{G} 76 \mathrm{~V}}$-GFP and wild type mice was not accompanied by changes in proteasome activity. No difference in disease onset and progression was reported as compared to $\mathrm{Tg}(\mathrm{PG} 14)$ mice that do not express $\mathrm{Ub}^{\mathrm{G} 76 \mathrm{~V}}$-GFP. In addition, proteasome activity was not altered in primary CGN isolated from $\mathrm{Tg}$ mice expressing the D177N/128V mutation (murine PrP numbering). A similar mutation in humans is associated with fCJD (Ref. 233).

A genetic basis for the role of the UPS in TSEs was found in a recent study showing association between the haplotypes of the HECTD2 gene, encoding an E3 ubiquitin ligase, and the susceptibility to SCJD, vCJD and kuru in humans, and the length of the incubation time in mice (Ref. 234). Genotype-associated differential expression of Hectd 2 mRNA was also reported in mouse brains and human lymphocytes, with a significant up-regulation of Hectd2 expression in mice during the course of prion disease (Ref. 234).

While different mechanisms of neurodegeneration may occur in inherited TSEs and prion forms acquired by infection (Refs 235, 236), further research is needed to reconcile the existing discrepancies. In this line, of particular relevance are the findings derived from the proteomic analysis of RML-infected wild-type and Tg44 mice described above (Ref. 178).

Nicotine adenine dinucleotide $\left(N A D^{+}\right)$starvation. Following up on the empirical observation that changes in the composition of culture medium delayed neuroblastoma cell death after exposure to TPrP, Zhou and colleagues identified $\mathrm{NAD}^{+}$starvation as a novel mechanism of neuronal death in protein misfolding neurodegenerative diseases (Fig. 2, solid grey line) (Ref. 191). $\mathrm{NAD}^{+}$levels were significantly reduced in neuroblastoma cells three days following TPrP treatment, but not after exposure to nontoxic monomeric $\operatorname{PrP}^{\mathrm{C}}$. Such an effect was normalised by the addition of $\mathrm{NAD}^{+}$or the $\mathrm{NAD}^{+}$precursor nicotinamide. Since $\mathrm{NAD}^{+}$is a co-enzyme critical for energy production, redox homeostasis, $\mathrm{Ca}^{2+}$ signalling, and post-translational modifications, the authors underlined $\mathrm{NAD}^{+}$starvation and related metabolic failure as the most likely primary cause of neuronal death. $\mathrm{NAD}^{+}$ levels were elevated in astrocytes, a finding consistent with the previously observed resistance to TPrP toxicity (Ref. 170). Because reactive astroglyosis is a well defined characteristic of prion pathology with astrocytes replacing dying neurons (Ref. 237), it was suggested that elevated astrocytic NAD ${ }^{+}$levels compensated the reduced neuronal $\mathrm{NAD}^{+}$quantities, therefore explaining the unchanged levels of total $\mathrm{NAD}^{+}$ observed in prion afflicted mouse brains (Ref. 191). Further investigations demonstrated that $\mathrm{NAD}^{+}$depletion triggered autophagy activation, probably as a result of limited ATP supply, suggesting that autophagy, similarly to apoptosis, is a secondary mechanisms of neurodegeneration in prion diseases (Ref. 191).

\section{Therapeutic approaches}

At present, no efficient therapies are available to treat prion diseases (Ref. 238). Therapies can be directed to various targets: $\operatorname{PrP}^{\mathrm{C}}$, $\operatorname{PrP}^{\mathrm{TSE}}, \operatorname{PrP}^{\mathrm{C}}$ to $\operatorname{PrP}^{\mathrm{TSE}}$ conversion, and specific neurodegenerative pathways. To date, most approaches are based on inhibiting $\operatorname{PrP}^{\mathrm{TSE}}$ accumulation. Although targeting $\operatorname{PrP}^{\mathrm{TSE}}$ is a potentially powerful approach, it has some drawbacks. Since no pre-symptomatic tests are currently available to diagnose prion diseases, these treatments are administered during the clinical phase, after $\operatorname{PrP}^{\mathrm{TSE}}$ accumulation has long been established. However, it is well known now that loss of synapses and dendrites followed by synaptic dysfunction are early events in prion neurodegeneration preceding $\mathrm{PrP}^{\mathrm{TSE}}$ accumulation. Therefore, therapies aiming at removing $\operatorname{PrP}^{\mathrm{TSE}}$ aggregates may provide little benefit to clinically sick patients. Moreover, in light of the prevalent view that oligomeric rather than fibrillar accumulations of $\operatorname{PrP}^{\mathrm{TSE}}$ are the neurotoxic species, breaking up $\operatorname{PrP}^{\mathrm{TSE}}$ aggregates may exacerbate or even prolong the disease.

Alternatively, targeting $\operatorname{PrP}^{\mathrm{C}}$ offers a number of advantages. PrP-null mice, goats, and cattle are refractory to prion infection and live normal lives (Refs 48, $50,51,52,53,63)$. Likewise, knocking out neuronal $\operatorname{PrP}^{\mathrm{C}}$ half-way through the incubation period prevents the development of prion disease (Ref. 160). Unfortunately, transgenic strategies to eliminate $\operatorname{PrP}^{\mathrm{C}}$ expression are far from being applicable to human therapy at the present time. Instead, it is possible to screen for, or design, pharmaceutical inhibitors of $\operatorname{PrP}^{\mathrm{C}}$ biogenesis. Notwithstanding, uncertainty arises from zebrafish studies highlighting the importance of $\operatorname{PrP}^{\mathrm{C}}$ in cell-to-cell adhesion, and until the observed phenotypes in zebrafish and mammalian knock-out models are further explained, approaches targeting $\operatorname{PrP}^{\mathrm{C}}$ expression should be considered with caution. In addition, $\operatorname{PrP}^{\mathrm{C}}$ has been shown to negatively regulate BACE-1 ( $\beta$-site APP cleaving enzyme 1$)$, and increased levels of $A \beta_{1-40}$ and $A \beta_{1-42}$ have been found in PrP null mice, in mice harboring mutations in the Prnp gene associated with some forms of fCJD and GSS, as well as in mice infected with various strains of $\operatorname{PrP}^{\mathrm{TSE}}$ (Ref. 122). Thus, removal of $\operatorname{PrP}^{\mathrm{C}}$ or interfering with its physiological function may contribute to the development of AD.

In light of recent observations (Ref. 222), targeting the UPR appears as a very attractive approach. Reduction of eIF $2 \alpha-P$ levels by lentiviral-induced overexpression of an eIF $2 \alpha-P$ specific phosphatase, rescued the pathologic phenotype associated with sustained translational repression during ER stress, and significantly increased mouse survival in scrapie infected Tg37 transgenic mice (Ref. 222). Moreover, pharmacological modification of the UPR by selectively inhibiting PERK phosphorylation and activity upstream of 
eIF2 $\alpha$, prevented translational repression with subsequent neuroprotection. The concomitant pancreatic toxicity observed in treated mice, which led to significant body weight loss and a mild increase of glucose levels in blood, questioned the clinical application of UPR inhibitors and stimulated the search for new compounds with reduced toxicity (Ref. 239). Additional studies from the same group identified the small molecule ISRIB (integrated stress response inhibitor), which prevents translation inhibition downstream of eIF2 $\alpha-P$, as a good drug candidate. Daily intraperitoneal administration of ISRIB to prion infected $\operatorname{Tg} 37^{+/-}$mice from 7 weeks post infection, showed that partial restoration of global translation rates sufficed to confer neuroprotection in the absence of pancreatic toxicity. Notably, despite significantly increasing mouse survival as compared to untreated controls, ISRIB administration resulted in significant body weight loss similarly to PERK inhibition (Ref. 240). Understanding whether the observed weight loss results from UPR inhibition, it is a side effect of ISRIB treatment, or else it arises as a consequence of persistent prion infection will have important implications in the clinical implementation of this and similar drugs (Ref. 240).

One of the most promising therapies for treating human prion diseases is passive immunisation with anti-PrP antibodies (Refs 241, 242). This strategy has been extended to several neurodegenerative diseases, including TSEs, encouraged by the observed reduction in amyloid plaque burden in a transgenic mouse model of AD treated with $\mathrm{A} \beta$-directed antibodies (Ref. 243). Additionally, several in vitro studies demonstrate the feasibility of this approach to cure or prevent cellular infection with several strains of prions (Refs 244, 245). Importantly, a recent in vivo study demonstrated $\mathrm{PrP}^{\mathrm{TSE}}$ clearance, and increased survival, after passive immunisation with anti-PrP monoclonal antibodies administered before disease onset (Ref. 246). These findings indicate that therapeutic treatments aiming at blocking the conversion mechanism leading to $\operatorname{PrP}^{\mathrm{TSE}}$ generation are good approaches to treating prion diseases. Nonetheless, the practical application of these therapies depends upon the development of reliable diagnostic tests to allow early antibody administration.

Active immunisation has been evaluated in a number of studies with highly encouraging outcomes [reviewed in (Refs 241, 242)]. Initial studies with bacteriallyexpressed recombinant full length $\mathrm{PrP}^{\mathrm{C}}$ and various PrP peptides served to highlight the difficulty in breaking tolerance to a self-protein. Additionally, they stressed the importance of breaking tolerance to raise antibodies interfering with $\operatorname{PrP}^{\mathrm{TSE}}$ replication and propagation, while at the same time, minimising an autoimmune response (Ref. 241). Along these lines, mucosal immunisation using bacterial vectors has been suggested as an ideal means to achieve immunomodulation by inducing a secretory IgA response with limited systemic IgG levels, and minimal autoimmune inflammatory effects. This approach was validated in vivo when wild-type mice previously immunised with a mouse $\mathrm{PrP}^{\mathrm{C}}$-expressing attenuated Salmonella strain, showed resistance to orally administered prions. These mice were characterised by significant anti-PrP mucosal $\operatorname{IgA}$ and systemic anti-PrP IgG response (Ref. 247). Mucosal immunisation to prevent CWD infection has also been attempted. White-tailed deer immunisation with attenuated Salmonella expressing deer-PrP ${ }^{\mathrm{C}}$ resulted in increased titers of anti-PrP $\operatorname{IgG}$ and $\operatorname{IgM}$ in the plasma, and anti-PrP IgA in saliva and faeces as compared with control deer, showing for the first time the generation of humoral responses against self-PrP in the biological fluids of large cervid animals (Refs 241, 248). Vaccinated deer had a significantly prolonged incubation period than control animals following oral infection with a $100 \%$ lethal dose of CWD prions. One deer in the vaccinated group remained free of CWD symptoms and $\mathrm{PrP}^{\mathrm{TSE}}$ for 3 years and 7 months, as determined by immunohistochemical evaluation of tonsil and rectoanal mucosa-associated lymphoid tissue biopsies. Importantly, this animal showed the highest levels of mucosal and systemic immune response (Ref. 248).

This study revealed the feasibility of utilising bacterial vectors to induce mucosal immunisation and prevent prion disease infection, albeit being at an early stage of development. Mucosal immunisation represents an important approach to prevent acquired forms of TSE in humans (vCJD), and interrupt transmission of BSE, scrapie, and CWD in animals in which the gut is the major route of entry. Additionally, monoclonal antibodies produced in vaccinated animals could be isolated and used for passive immunisation, extending the potential clinical application of these approaches to other forms of TSE of different aetiology (Ref. 241).

The recent discovery of $\mathrm{NAD}^{+}$starvation as potential cause of neuronal death, led to the therapeutical investigation of $\mathrm{NAD}^{+}$replenishment in in vivo models of mouse scrapie. Stereotaxic injections of TPrP in the presence or absence of $\mathrm{NAD}^{+}$resulted in TPrP toxicity abrogation in a dose-dependent manner (Ref. 191). When $\mathrm{NAD}^{+}$was intra-nasally administered at disease onset, mice infected with RML, showed slower disease progression and weight loss than phosphate-buffered saline (PBS)-treated control mice. A similar result was obtained when RML-infected mice were treated during the clinical phase of the disease. Although no differences in survival were observed between treated and control groups, $\mathrm{NAD}^{+}$administration significantly increased motor function in mice (Ref. 191).

\section{Concluding remarks}

Prion diseases are devastating disorders of the CNS. At the present time there is no efficient treatment or cure for these diseases, and therefore, affected individuals die within months after the first clinical symptoms appear. Identification of the neurotoxic molecule(s) and the cellular pathways leading to neurodegeneration 
would facilitate the development of new therapies. Likewise, development of early, noninvasive diagnostic tests is extremely important; epidemiologically, to prevent secondary transmissions, and therapeutically, to allow the administration of effective therapies before extensive brain damage takes place. This is of particular relevance in the case of hereditary/genetic forms of TSE.

Understanding the biology underlying prionmediated neurotoxicity is challenging given the unprecedented nature of the infectious agent. $\mathrm{PrP}^{\mathrm{TSE}}$ replicates by conferring its aberrant conformation onto a cellular protein, $\operatorname{PrP}^{\mathrm{C}}$. Studies conducted with $\mathrm{PrP}^{-/-}$ mice indicated that loss of $\mathrm{PrP}^{\mathrm{C}}$ function cannot account for prion neurotoxicity, as these mice show neither a deleterious phenotype nor altered lifespan. Experimental evidence has been accumulated demonstrating the dissociation between $\operatorname{PrP}^{\mathrm{C}}$ to $\operatorname{PrP}^{\mathrm{TSE}}$ conversion with accumulation of the latter and neurotoxicity. While $\mathrm{PrP}^{\mathrm{C}}$ expression is prerequisite for prion neuroinvasion and propagation, its requirement at the neuronal membrane for neurotoxicity is still matter of controversy. Intriguing is the fact that astrocytes are refractory to TPrP toxicity, similarly to findings derived from the post-natal removal of $\operatorname{PrP}^{\mathrm{C}}$ expression highlighted above. These observations suggest that the neurotoxic entity, namely $\mathrm{TPrP}$ or $\operatorname{PrP}^{\mathrm{L}}$, should be generated within neurons to cause toxicity to these cells. Importantly, the confirmation of these hypotheses relies on the successful isolation of these molecules from naturally or experimentally induced TSE; task that remains highly elusive.

Similarly controversial is the nature of the entity responsible for the neurotoxic cascade observed in TSEs. Whether prion-related neurodegeneration is triggered by the gain of toxic function of low molecular weight $\operatorname{PrP}^{\mathrm{TSE}}$ oligomers, the generation of toxic intermediates, or the subversion of $\operatorname{PrP}^{\mathrm{C}}$ biological function remains to be elucidated. But in light of the heterogeneity in clinical and pathological presentation of this diverse group of disorders, it is very likely that distinct mechanisms are involved in TSE forms of different aetiology.

Altogether, the findings described in this review indicate that significant progress has been made in recent years towards the elucidation of prion-induced mechanisms of neurodegeneration and, more importantly, potential treatments to halt these devastating disorders. Further confirmation of these mechanisms can be accomplished by refining the identification of the molecules involved in the cellular pathways activated during neurodegeneration. Genetic and biochemical methods can be utilised to identify more precisely cellular partners interacting with variants of PrP molecules, and may reveal signalling cascades activated in TSEs and other neurodegenerative diseases that culminate in neuronal death. The involvement of identified partners will subsequently need to be validated in in vitro (cell cultures, organotypic slices, mini brains) and in vivo models of prion disease. This can be accomplished, for example, by deleting the expression of the identified molecules in cells or in mice and by creating double-knockout mice and evaluating the pathologic process under these conditions. Eventually, based on findings derived from these studies, appropriate early diagnostics and targeted treatments can be developed and implemented in real life to treat humans and animals.

\section{Acknowledgements}

We thank Donna Sobieski and Dr Erin Moritz for editorial assistance. Work in the laboratory of DAH is supported by grants from the National Institutes of Health (R01 NS065244 and R01 NS040975).

\section{References}

1. Prusiner S.B. (1982) Novel proteinaceous infectious particles cause scrapie. Science 216, 136-144

2. Prusiner S.B. (2012) Cell biology. A unifying role for prions in neurodegenerative diseases. Science 336, 1511-1513

3. Puoti G. et al. (2012) Sporadic human prion diseases: molecular insights and diagnosis. Lancet Neurology 11, 618-628

4. Moody K.M. et al. (2011) Sporadic fatal insomnia in a young woman: a diagnostic challenge: case report. BMC Neurology $\mathbf{1 1}, 136$

5. Notari S. et al. (2014) Transmission characteristics of variably protease-sensitive prionopathy. Emerging Infectious Diseases 20, 2006-2014

6. Diack A.B. et al. (2014) Variably protease-sensitive prionopathy, a unique prion variant with inefficient transmission properties. Emerging Infectious Diseases 20, 1969-1979

7. Gambetti P. et al. (2008) A novel human disease with abnormal prion protein sensitive to protease. Annals of Neurology 63, 697-708

8. Liberski P.P. and Budka H. (2004) Gerstmann-StrausslerScheinker disease. I. Human diseases. Folia Neuropathologica 42 (Suppl B), 120-140

9. Brown P. (1994) Transmissible human spongiform encephalopathy (Infectious cerebral amyloidosis): Creutzfeldt-Jakob Disease, Gerstmann-Sträussler-Scheinker Syndrome and Kuru. In Neurodegenerative Diseases (Calne D.B. ed.), p. 38. W.B.Saunders, Philadelphia

10. Gambetti P. et al. (1999) Inherited prion diseases. In Prion Biology and Diseases (Monograf $38 \mathrm{edn}$ ) (Prusiner S. ed.), p. 74. Cold Spring Harbor Laboratory Press, Cold Spring Harbor, New York

11. Mastrianni J.A. (1993) Genetic prion diseases. In GeneReviews(R) (Pagon R.A., Adam M.P., Ardinger H.H., Wallace S.E., Amemiya A., Bean L.J.H., Bird T.D., Fong C.T., Mefford H.C., Smith R.J.H. and Stephens K. eds), pp. 1993-2016. University of Washington, Seattle, WA

12. Will R.G. et al. (1996) A new variant of Creutzfeldt-Jakob disease in the UK. Lancet 347, 921-925

13. Brown P. et al. (2012) Iatrogenic Creutzfeldt-Jakob disease, final assessment. Emerging Infectious Diseases 18, 901-907

14. Liberski P.P. et al. (2012) Kuru: genes, cannibals and neuropathology. Journal of Neuropathology and Experimental Neurology 71, 92-103

15. Collinge J. et al. (2006) Kuru in the 21 st century - an acquired human prion disease with very long incubation periods. Lancet 367, 2068-2074

16. Gajdusek D.C. (1977) Unconventional viruses and the origin and disappearance of kuru. Science 197, 943-960

17. Alpers M.P. (1987) Epidemiology and clinical aspects of Kuru. In Prions (Prusiner S.B. and McKinley M.P. eds), p. 451-465. Academic Press, San Diego

18. Tange R.A., Troost D. and Limburg M. (1990) Progressive fatal dementia (Creutzfeldt-Jakob disease) in a patient who received homograft tissue for tympanic membrane closure. European Archives of Oto-rhino-laryngology 247, 199-201

19. Llewelyn C.A. et al. (2004) Possible transmission of variant Creutzfeldt-Jakob disease by blood transfusion. Lancet $\mathbf{3 6 3}$, 417-421 
20. Gillies M. et al. (2009) A retrospective case note review of deceased recipients of vCJD-implicated blood transfusions. Vox Sanguinis 97, 211-218

21. Peden A.H. et al. (2004) Preclinical vCJD after blood transfusion in a PRNP codon 129 heterozygous patient. Lancet 364, 527-529

22. Wroe S.J. et al. (2006) Clinical presentation and pre-mortem diagnosis of variant Creutzfeldt-Jakob disease associated with blood transfusion: a case report. Lancet 368, 20612067

23. Montagna P. et al. (2003) Familial and sporadic fatal insomnia. Lancet Neurology 2, 167-176

24. Hunter N. (1997) PrP genetics in sheep and the applications for scrapie and BSE. Trends in Microbiology 5, 331-334

25. Mead S. (2006) Prion disease genetics. European Journal of Human Genetics 14, 273-281

26. Kovacs G.G. and Budka H. (2009) Molecular pathology of human prion diseases. International Journal of Molecular Sciences 10, 976-999

27. Collinge J., Palmer M.S. and Dryden A.J. (1991) Genetic predisposition to iatrogenic Creutzfeldt-Jakob disease. Lancet 337, 1441-1442

28. Palmer M.S. et al. (1991) Homozygous prion protein genotype predisposes to sporadic Creutzfeldt-Jakob disease. Nature 352, 340-342

29. Palmer M.S. and Collinge J. (1993) Mutations and polymorphisms in the prion protein gene. Human Mutation 2, 168-173

30. Belt P.B. et al. (1995) Identification of five allelic variants of the sheep PrP gene and their association with natural scrapie. Journal of General Virology 76 (Pt 3), 509-517

31. Lee H.S. et al. (2001) Increased susceptibility to Kuru of carriers of the PRNP 129 methionine/methionine genotype. Journal of Infectious Diseases 183, 192-196

32. Gambetti P. et al. (2011) Molecular biology and pathology of prion strains in sporadic human prion diseases. Acta Neuropathologica 121, 79-90

33. Hill A.F. et al. (2003) Molecular classification of sporadic Creutzfeldt-Jakob disease. Brain 126 (Pt 6), 1333-1346

34. Collinge J. and Clarke A.R. (2007) A general model of prion strains and their pathogenicity. Science 318, 930-936

35. Sabuncu E. et al. (2003) PrP polymorphisms tightly control sheep prion replication in cultured cells. Journal of Virology 77, 2696-2700

36. Rigter A. and Bossers A. (2005) Sheep scrapie susceptibilitylinked polymorphisms do not modulate the initial binding of cellular to disease-associated prion protein prior to conversion. Journal of General Virology 86 (Pt 9), 2627-2634

37. Thackray A.M. et al. (2011) Emergence of multiple prion strains from single isolates of ovine scrapie. Journal of General Virology 92 (Pt 6), 1482-1491

38. Hill A.F. et al. (1997) The same prion strain causes vCJD and BSE. Nature 389, 448-450, 526

39. Collinge J. (2001) Prion diseases of humans and animals: their causes and molecular basis. Annual Review of Neuroscience 24, 519-550

40. Prusiner S.B. (1986) Prions are novel infectious pathogens causing scrapie and Creutzfeldt-Jakob disease. BioEssays 5, 281-286

41. Weissmann C. et al. (2011) Prions on the move. EMBO Reports 12, 1109-1117

42. Unterberger U., Voigtlander T. and Budka H. (2005) Pathogenesis of prion diseases. Acta Neuropathologica 109, $32-48$

43. Stahl N. et al. (1987) Scrapie prion protein contains a phosphatidylinositol glycolipid. Cell 51, 229-240

44. Donne D.G. et al. (1997) Structure of the recombinant fulllength hamster prion protein $\operatorname{PrP}(29-231)$ : the $\mathrm{N}$ terminus is highly flexible. Proceedings of the National Academy of Sciences of the United States of America 94, 13452-13457

45. Altmeppen H.C. et al. (2013) Roles of endoproteolytic alphacleavage and shedding of the prion protein in neurodegeneration. FEBS Journal 280, 4338-4347

46. Riek R. et al. (1997) NMR characterization of the full-length recombinant murine prion protein, $\operatorname{mPrP}(23-231)$. FEBS Letters 413, 282-288

47. Riek R. et al. (1998) Prion protein NMR structure and familial human spongiform encephalopathies. Proceedings of the
National Academy of Sciences of the United States of America 95, 11667-11672

48. Bueler H. et al. (1992) Normal development and behaviour of mice lacking the neuronal cell-surface PrP protein. Nature 356, 577-582

49. Manson J.C. et al. (1994) 129/Ola mice carrying a null mutation in PrP that abolishes mRNA production are developmentally normal. Molecular Neurobiology 8, 121-127

50. Richt J.A. et al. (2007) Production of cattle lacking prion protein. Nature Biotechnology 25, 132-138

51. Yu G. et al. (2006) Functional disruption of the prion protein gene in cloned goats. Journal of General Virology $87(\mathrm{Pt} 4)$, 1019-1027

52. Yu G. et al. (2009) Generation of goats lacking prion protein. Molecular Reproduction and Development 76, 3

53. Benestad S.L. et al. (2012) Healthy goats naturally devoid of prion protein. Veterinary Research 43, 87

54. Mallucci G.R. et al. (2002) Post-natal knockout of prion protein alters hippocampal CA1 properties, but does not result in neurodegeneration. EMBO Journal 21, 202-210

55. Tobler I. et al. (1996) Altered circadian activity rhythms and sleep in mice devoid of prion protein. Nature 380, 639-642

56. Westergard L., Christensen H.M. and Harris D.A. (2007) The cellular prion protein $(\operatorname{PrP}(\mathrm{C}))$ : its physiological function and role in disease. Biochimica et Biophysica Acta 1772, 629-644

57. Wadsworth J.D., Asante E.A. and Collinge J. (2010) Review: contribution of transgenic models to understanding human prion disease. Neuropathology and Applied Neurobiology 36, 576-597

58. Nazor K.E., Seward T. and Telling G.C. (2007) Motor behavioral and neuropathological deficits in mice deficient for normal prion protein expression. Biochimica et Biophysica Acta 1772, 645-653

59. Collinge J. et al. (1994) Prion protein is necessary for normal synaptic function. Nature 370, 295-297

60. Manson J.C. et al. (1995) PrP gene dosage and long term potentiation. Neurodegeneration 4, 113-114

61. Striebel J.F., Race B. and Chesebro B. (2013) Prion protein and susceptibility to kainate-induced seizures: genetic pitfalls in the use of PrP knockout mice. Prion 7, 280-285

62. Steele A.D., Lindquist S. and Aguzzi A. (2007) The prion protein knockout mouse: a phenotype under challenge. Prion 1, 83-93

63. Bueler H. et al. (1993) Mice devoid of PrP are resistant to scrapie. Cell 73, 1339-1347

64. Sailer A. et al. (1994) No propagation of prions in mice devoid of PrP. Cell 77, 967-968

65. Manson J.C. et al. (1994) PrP gene dosage determines the timing but not the final intensity or distribution of lesions in scrapie pathology. Neurodegeneration 3, 331-340

66. Kretzschmar H.A. et al. (1986) Scrapie prion proteins are synthesized in neurons. The American Journal of Pathology 122, $1-5$

67. Moser M. et al. (1995) Developmental expression of the prion protein gene in glial cells. Neuron 14, 509-517

68. Brown H.R. et al. (1990) The mRNA encoding the scrapie agent protein is present in a variety of non-neuronal cells. Acta Neuropathologica 80, 1-6

69. Tanji K. et al. (1995) Analysis of PrPc mRNA by in situ hybridization in brain, placenta, uterus and testis of rats. Intervirology 38, 309-315

70. McLennan N.F. et al. (2001) In situ hybridization analysis of PrP mRNA in human CNS tissues. Neuropathology and Applied Neurobiology 27, 373-383

71. Bendheim P.E. et al. (1992) Nearly ubiquitous tissue distribution of the scrapie agent precursor protein. Neurology 42, 149156

72. Ford M.J. et al. (2002) A marked disparity between the expression of prion protein and its message by neurones of the CNS. Neuroscience 111, 533-551

73. Laine J. et al. (2001) Cellular and subcellular morphological localization of normal prion protein in rodent cerebellum. European Journal of Neuroscience 14, 47-56

74. Gorodinsky A. and Harris D.A. (1995) Glycolipid-anchored proteins in neuroblastoma cells form detergent-resistant complexes without caveolin. Journal of Cell Biology 129, 19

75. Naslavsky N. et al. (1997) Characterization of detergent-insoluble complexes containing the cellular prion protein and its 
scrapie isoform. Journal of Biological Chemistry 272, 63246331

76. Jacobson K. and Dietrich C. (1999) Looking at lipid rafts? Trends in Cell Biology 9, 87-91

77. Mouillet-Richard S. et al. (2000) Signal transduction through prion protein. Science 289, 1925-1928

78. Chen S. et al. (2003) Prion protein as trans-interacting partner for neurons is involved in neurite outgrowth and neuronal survival. Molecular and Cellular Neurosciences 22, 227-233

79. Graner E. et al. (2000) Cellular prion protein binds laminin and mediates neuritogenesis. Molecular Brain Research 76, 85-92

80. Mironov A. Jr et al. (2003) Cytosolic prion protein in neurons. Journal of Neuroscience 23, 7183-7193

81. Fournier J.G. et al. (1995) Ultrastructural localization of cellular prion protein $(\mathrm{PrPc})$ in synaptic boutons of normal hamster hippocampus. Comptes Rendus de l'Académie des Sciences Series III 318, 339-344

82. Herms J. et al. (1999) Evidence of presynaptic location and function of the prion protein. Journal of Neuroscience 19 , 8866-8875

83. Haeberle A.M. et al. (2000) Synaptic prion protein immunoreactivity in the rodent cerebellum. Microscopy Research and Technique 50, 66-75

84. Moya K.L. et al. (2000) Immunolocalization of the cellular prion protein in normal brain. Microscopy Research and Technique 50, 58-65

85. Spielhaupter C. and Schatzl H.M. (2001) PrPC directly interacts with proteins involved in signaling pathways. Journal of Biological Chemistry 276, 44604-44612

86. Magalhaes A.C. et al. (2002) Endocytic intermediates involved with the intracellular trafficking of a fluorescent cellular prion protein. Journal of Biological Chemistry 277, 33311-33318

87. Senatore A. et al. (2012) Mutant PrP suppresses glutamatergic neurotransmission in cerebellar granule neurons by impairing membrane delivery of VGCC alpha(2)delta-1 Subunit. Neuron 74, 300-313

88. Robinson S.W. et al. (2014) Prion protein facilitates synaptic vesicle release by enhancing release probability. Human Molecular Genetics 23, 4581-4596

89. Ma J., Wollmann R. and Lindquist S. (2002) Neurotoxicity and neurodegeneration when PrP accumulates in the cytosol. Science 298, 1781-1785

90. Hofmann J. and Vorberg I. (2013) Life cycle of cytosolic prions. Prion 7, 369-377

91. Atoji Y. and Ishiguro N. (2009) Distribution of the cellular prion protein in the central nervous system of the chicken. Journal of Chemical Neuroanatomy 38, 292-301

92. Malaga-Trillo E. and Sempou E. (2009) PrPs: Proteins with a purpose: Lessons from the zebrafish. Prion 3, 129-133

93. Rivera-Milla E., Stuermer C.A. and Malaga-Trillo E. (2003) An evolutionary basis for scrapie disease: identification of a fish prion mRNA. Trends in Genetics 19, 72-75

94. Rivera-Milla E. et al. (2006) Disparate evolution of prion protein domains and the distinct origin of Doppel- and prion-related loci revealed by fish-to-mammal comparisons. FASEB Journal 20, 317-319

95. Miesbauer M. et al. (2006) Prion protein-related proteins from zebrafish are complex glycosylated and contain a glycosylphosphatidylinositol anchor. Biochemical and Biophysical Research Communications 341, 218-224

96. Malaga-Trillo E. et al. (2009) Regulation of embryonic cell adhesion by the prion protein. PLoS Biology 7, e55

97. Roucou X., Gains M. and LeBlanc A.C. (2004) Neuroprotective functions of prion protein. Journal of Neuroscience Research 75, 153-161

98. Pauly P.C. and Harris D.A. (1998) Copper stimulates endocytosis of the prion protein. Journal of Biological Chemistry 273, 33107-33110

99. Mange A. et al. (2002) PrP-dependent cell adhesion in N2a neuroblastoma cells. FEBS Letters 514, 159-162

100. Bremer J. et al. (2010) Axonal prion protein is required for peripheral myelin maintenance. Nature Neuroscience 13, 310-318

101. Nishida N. et al. (1999) A mouse prion protein transgene rescues mice deficient for the prion protein gene from
Purkinje cell degeneration and demyelination. Laboratory Investigation 79, 689-697

102. Oh J.M. et al. (2008) The involvement of cellular prion protein in the autophagy pathway in neuronal cells. Molecular and Cellular Neurosciences 39, 238-247

103. Schmitt-Ulms G. et al. (2009) Evolutionary descent of prion genes from the ZIP family of metal ion transporters. PLoS ONE 4, e7208

104. Brown D.R. et al. (1999) Normal prion protein has an activity like that of superoxide dismutase. Biochemical Journal 344 (Pt 1), 1-5

105. Brown D.R. et al. (1997) The cellular prion protein binds copper in vivo. Nature 390, 684-687

106. Jones S. et al. (2005) Recombinant prion protein does not possess SOD-1 activity. Biochemical Journal 392 (Pt 2), 309-312

107. Hutter G., Heppner F.L. and Aguzzi A. (2003) No superoxide dismutase activity of cellular prion protein in vivo. Biological Chemistry 384, 1279-1285

108. Davies P. et al. (2011) Contribution of individual histidines to prion protein copper binding. Biochemistry 50, 10781-10791

109. Sakudo A. et al. (2005) PrP cooperates with STI1 to regulate SOD activity in PrP-deficient neuronal cell line. Biochemical and Biophysical Research Communications 328, 14-19

110. Kurschner C. and Morgan J.I. (1996) Analysis of interaction sites in homo- and heteromeric complexes containing Bcl-2 family members and the cellular prion protein. Molecular Brain Research 37, 249-258

111. Kurschner C. and Morgan J.I. (1995) The cellular prion protein (PrP) selectively binds to Bcl-2 in the yeast twohybrid system. Molecular Brain Research 30, 165-168

112. Kuwahara C. et al. (1999) Prions prevent neuronal cell-line death. Nature 400, 225-226

113. Bounhar Y. et al. (2001) Prion protein protects human neurons against Bax-mediated apoptosis. Journal of Biological Chemistry 276, 39145-39149

114. Li A. and Harris D.A. (2005) Mammalian prion protein suppresses Bax-induced cell death in yeast. Journal of Biological Chemistry 280, 17430-17434

115. Chiesa R. et al. (2005) Bax deletion prevents neuronal loss but not neurological symptoms in a transgenic model of inherited prion disease. Proceedings of the National Academy of Sciences of the United States of America 102, 238-243

116. Zhang C.C. et al. (2006) Prion protein is expressed on longterm repopulating hematopoietic stem cells and is important for their self-renewal. Proceedings of the National Academy of Sciences of the United States of America 103, 2184-2189

117. Zomosa-Signoret V. et al. (2008) Physiological role of the cellular prion protein. Veterinary Research 39, 9

118. Ingram R.J. et al. (2009) A role of cellular prion protein in programming $\mathrm{T}$-cell cytokine responses in disease. FASEB Journal 23, 1672-1684

119. Kubosaki A. et al. (2003) Expression of normal cellular prion protein $(\operatorname{PrP}(\mathrm{c}))$ on $\mathrm{T}$ lymphocytes and the effect of copper ion: Analysis by wild-type and prion protein gene-deficient mice. Biochemical and Biophysical Research Communications 307, 810-813

120. Ballerini C. et al. (2006) Functional implication of cellular prion protein in antigen-driven interactions between $\mathrm{T}$ cells and dendritic cells. Journal of Immunology 176, 72547262

121. Gunther E.C. and Strittmatter S.M. (2010) Beta-amyloid oligomers and cellular prion protein in Alzheimer's disease. Journal of Molecular Medicine (Berl) 88, 331-338

122. Parkin E.T. et al. (2007) Cellular prion protein regulates betasecretase cleavage of the Alzheimer's amyloid precursor protein. Proceedings of the National Academy of Sciences of the United States of America 104, 11062-11067

123. Lauren J. et al. (2009) Cellular prion protein mediates impairment of synaptic plasticity by amyloid-beta oligomers. Nature 457, 1128-1132

124. Barry A.E. et al. (2011) Alzheimer's disease brain-derived amyloid-beta-mediated inhibition of LTP in vivo is prevented by immunotargeting cellular prion protein. The Journal of Neuroscience 31, 7259-7263

125. Freir D.B. et al. (2011) Interaction between prion protein and toxic amyloid [beta] assemblies can be therapeutically targeted at multiple sites. Nature Communications 2, 336 
126. Gimbel D.A. et al. (2010) Memory impairment in transgenic Alzheimer mice requires cellular prion protein. Journal of Neuroscience 30, 6367-6374

127. Kudo W. et al. (2012) Cellular prion protein is essential for oligomeric amyloid-beta-induced neuronal cell death. Human Molecular Genetics 21, 1138-1144

128. Bate C. and Williams A. (2011) Amyloid-beta-induced synapse damage is mediated via cross-linkage of cellular prion proteins. Journal of Biological Chemistry 286, 3795537963

129. Kessels H.W. et al. (2010) The prion protein as a receptor for amyloid-[beta]. Nature 466, E3-E4

130. Calella A.M. et al. (2010) Prion protein and Abeta-related synaptic toxicity impairment. EMBO Molecular Medicine 2, 306314

131. Balducci C. et al. (2010) Synthetic amyloid-beta oligomers impair long-term memory independently of cellular prion protein. Proceedings of the National Academy of Sciences of the United States of America 107, 2295-2300

132. Cisse M. et al. (2011) Ablation of cellular prion protein does not ameliorate abnormal neural network activity or cognitive dysfunction in the J20 line of human amyloid precursor protein transgenic mice. Journal of Neuroscience 31, $10427-$ 10431

133. Rial D. et al. (2012) Overexpression of cellular prion protein $(\operatorname{PrP}(\mathrm{C}))$ prevents cognitive dysfunction and apoptotic neuronal cell death induced by amyloid-beta (Abeta 1-40) administration in mice. Neuroscience 215, 79-89

134. Resenberger U.K. et al. (2011) The cellular prion protein mediates neurotoxic signalling of beta-sheet-rich conformers independent of prion replication. EMBO Journal 30, 2057-2070

135. You H. et al. (2012) Abeta neurotoxicity depends on interactions between copper ions, prion protein, and N-methyl-Daspartate receptors. Proceedings of the National Academy of Sciences of the United States of America 109, 1737-1742

136. Um J.W. et al. (2012) Alzheimer amyloid-beta oligomer bound to postsynaptic prion protein activates Fyn to impair neurons. Nature Neuroscience 15, 1227-1235

137. Kovacs G.G. and Budka H. (2008) Prion diseases: from protein to cell pathology. American Journal of Pathology 172, 555-565

138. Sikorska B. et al. (2009) Ultrastructural study of florid plaques in variant Creutzfeldt-Jakob disease: a comparison with amyloid plaques in kuru, sporadic Creutzfeldt-Jakob disease and Gerstmann-Straussler-Scheinker disease. Neuropathology and Applied Neurobiology 35, 46-59

139. Forloni G. et al. (1993) Neurotoxicity of a prion protein fragment. Nature 362, 543-546

140. Hetz C. et al. (2003) Caspase-12 and endoplasmic reticulum stress mediate neurotoxicity of pathological prion protein. EMBO Journal 22, 5435-5445

141. Budka H. (2000) Histopathology and immunohistochemistry of human transmissible spongiform encephalopathies (TSEs). Archives of Virology Supplementum 16, 135-142

142. Zou W.Q. and Gambetti P. (2007) Prion: the chameleon protein. Cellular and Molecular Life Sciences 64, 32663270

143. Yuan J. et al. (2006) Insoluble aggregates and protease-resistant conformers of prion protein in uninfected human brains. Journal of Biological Chemistry 281, 34848-34858

144. Hsiao K.K. et al. (1994) Serial transmission in rodents of neurodegeneration from transgenic mice expressing mutant prion protein. Proceedings of the National Academy of Sciences of the United States of America 91, 9126-9130

145. Tateishi J. et al. (1995) First experimental transmission of fatal familial insomnia. Nature 376, 434-435

146. Hayward P.A., Bell J.E. and Ironside J.W. (1994) Prion protein immunocytochemistry: reliable protocols for the investigation of Creutzfeldt-Jakob disease. Neuropathology and Applied Neurobiology 20, 375-383

147. Collinge J. et al. (1995) Transmission of fatal familial insomnia to laboratory animals. Lancet 346, 569-570

148. Sandberg M.K. et al. (2014) Prion neuropathology follows the accumulation of alternate prion protein isoforms after infective titre has peaked. Nature Communications 5, 4347

149. Chesebro B. et al. (2010) Fatal transmissible amyloid encephalopathy: a new type of prion disease associated with lack of prion protein membrane anchoring. PLoS Pathogens 6, e1000800

150. Bueler H. et al. (1994) High prion and PrPSc levels but delayed onset of disease in scrapie-inoculated mice heterozygous for a disrupted PrP gene. Molecular Medicine 1, 19-30

151. Sandberg M.K. et al. (2011) Prion propagation and toxicity in vivo occur in two distinct mechanistic phases. Nature $\mathbf{4 7 0 ,}$ 540-542

152. Hill A.F. and Collinge J. (2003) Subclinical prion infection. Trends in Microbiology 11, 578-584

153. Race R. et al. (2001) Long-term subclinical carrier state precedes scrapie replication and adaptation in a resistant species: analogies to bovine spongiform encephalopathy and variant Creutzfeldt-Jakob disease in humans. Journal of Virology 75, 10106-10112

154. Thackray A.M. et al. (2002) Chronic subclinical prion disease induced by low-dose inoculum. Journal of Virology 76, 25102517

155. Thackray A.M., Klein M.A. and Bujdoso R. (2003) Subclinical prion disease induced by oral inoculation. Journal of Virology 77, 7991-7998

156. Asante E.A. et al. (2002) BSE prions propagate as either variant CJD-like or sporadic CJD-like prion strains in transgenic mice expressing human prion protein. EMBO Journal 21, 6358-6366

157. Hill A.F. et al. (2000) Species-barrier-independent prion replication in apparently resistant species. Proceedings of the National Academy of Sciences of the United States of America 97, 10248-10253

158. Brandner S. et al. (1996) Normal host prion protein necessary for scrapie-induced neurotoxicity. Nature 379, 339-343

159. Aguzzi A. et al. (1998) Use of brain grafts to study the pathogenesis of prion diseases. Essays in Biochemistry 33, 133-147

160. Mallucci G. et al. (2003) Depleting neuronal PrP in prion infection prevents disease and reverses spongiosis. Science 302, 871-874

161. Kazlauskaite J. et al. (2005) An unusual soluble beta-turn-rich conformation of prion is involved in fibril formation and toxic to neuronal cells. Biochemical and Biophysical Research Communications 328, 292-305

162. Masel J., Genoud N. and Aguzzi A. (2005) Efficient inhibition of prion replication by $\operatorname{PrP}-\mathrm{Fc}(2)$ suggests that the prion is a $\mathrm{PrP}(\mathrm{Sc})$ oligomer. Journal of Molecular Biology 345, 1243 1251

163. Haass C. and Selkoe D.J. (2007) Soluble protein oligomers in neurodegeneration: lessons from the Alzheimer's amyloid beta-peptide. Nature Reviews. Molecular Cell Biology 8, 101-112

164. Weissmann C. et al. (2002) Molecular biology of prions. Acta Neurobiologiae Experimentalis 62, 153-166

165. Simoneau S. et al. (2007) In vitro and in vivo neurotoxicity of prion protein oligomers. PLoS Pathogens 3, e125

166. Novitskaya V. et al. (2006) Amyloid fibrils of mammalian prion protein are highly toxic to cultured cells and primary neurons. Journal of Biological Chemistry 281, 13828-13836

167. Brandner S. et al. (1996) Normal host prion protein (PrPC) is required for scrapie spread within the central nervous system. Proceedings of the National Academy of Sciences of the United States of America 93, 13148-13151

168. Harris D.A. and True H.L. (2006) New insights into prion structure and toxicity. Neuron 50, 353-357

169. Chesebro B. et al. (2005) Anchorless prion protein results in infectious amyloid disease without clinical scrapie. Science 308, 1435-1439

170. Zhou M. et al. (2012) Highly neurotoxic monomeric alphahelical prion protein. Proceedings of the National Academy of Sciences of the United States of America 109, 3113-3118

171. Halliday M., Radford H. and Mallucci G.R. (2014) Prions: generation and spread versus neurotoxicity. Journal of Biological Chemistry 289, 19862-19868

172. Trifilo M.J. et al. (2006) Prion-induced amyloid heart disease with high blood infectivity in transgenic mice. Science 313, 94-97

173. Klingeborn M. et al. (2011) Crucial role for prion protein membrane anchoring in the neuroinvasion and neural spread of prion infection. Journal of Virology 85, 1484-1494

174. Ghetti B. et al. (1996) Vascular variant of prion protein cerebral amyloidosis with tau-positive neurofibrillary tangles: the 
phenotype of the stop codon 145 mutation in PRNP. Proceedings of the National Academy of Sciences of the United States of America 93, 744-748

175. Revesz T. et al. (2009) Genetics and molecular pathogenesis of sporadic and hereditary cerebral amyloid angiopathies. Acta Neuropathologica 118, 115-130

176. Jansen C. et al. (2010) Prion protein amyloidosis with divergent phenotype associated with two novel nonsense mutations in PRNP. Acta Neuropathologica 119, 189-197

177. Gambetti P. et al. (2003) Sporadic and familial CJD: classification and characterisation. British Medical Bulletin 66, 213239

178. Moore R.A. et al. (2014) Proteomics analysis of amyloid and nonamyloid prion disease phenotypes reveals both common and divergent mechanisms of neuropathogenesis. Journal of Proteome Research 13, 4620-4634

179. Budka H. (2003) Neuropathology of prion diseases. British Medical Bulletin 66, 121-130

180. Klionsky D.J. (2000) Autophagy as a regulated pathway of cellular degradation. Science 290, 1717-1721

181. Heiseke A., Aguib Y. and Schatzl H.M. (2010) Autophagy, prion infection and their mutual interactions. Current Issues in Molecular Biology 12, 11

182. Rubinsztein D.C. et al. (2005) Autophagy and its possible roles in nervous system diseases, damage and repair. Autophagy 1, 11-22

183. Boellaard J.W., Schlote W. and Tateishi J. (1989) Neuronal autophagy in experimental Creutzfeldt-Jakob's disease. Acta Neuropathologica 78, 410-418

184. Liberski P.P., Gajdusek D. and Brown P. (2002) How do neurons degenerate in prion diseases or transmissible spongiform encephalopathies (TSEs): neuronal autophagy revisited. Acta Neurobiologiae Experimentalis 62, 7

185. Liberski P.P. et al. (2004) Neuronal cell death in transmissible spongiform encephalopathies (prion diseases) revisited: from apoptosis to autophagy. International Journal of Biochemistry \& Cell Biology 36, 2473-2490

186. Beranger F. et al. (2008) Trehalose impairs aggregation of PrPSc molecules and protects prion-infected cells against oxidative damage. Biochemical and Biophysical Research Communications 374, 44-48

187. Aguib Y. et al. (2009) Autophagy induction by trehalose counter-acts cellular prion-infection. Autophagy 5, 9

188. Heiseke A. et al. (2009) Lithium induces clearance of protease resistant prion protein in prion-infected cells by induction of autophagy. Journal of Neurochemistry 109, 25-34

189. Ertmer A. et al. (2004) The tyrosine kinase inhibitor STI571 induces cellular clearance of PrPSc in prion-infected cells. Journal of Biological Chemistry 279, 41918-41927

190. Yun S.W. et al. (2007) The tyrosine kinase inhibitor imatinib mesylate delays prion neuroinvasion by inhibiting prion propagation in the periphery. Journal of Neurovirology 13, 328-337

191. Zhou M. et al. (2015) Neuronal death induced by misfolded prion protein is due to $\mathrm{NAD}^{+}$depletion and can be relieved in vitro and in vivo by $\mathrm{NAD}^{+}$replenishment. Brain $138(\mathrm{Pt}$ 4), 992-1008

192. Cortes C.J. et al. (2012) Rapamycin delays disease onset and prevents PrP plaque deposition in a mouse model of Gerstmann-Straussler-Scheinker disease. Journal of Neuroscience 32, 12396-12405

193. Giese A. et al. (1995) Neuronal cell death in scrapie-infected mice is due to apoptosis. Brain Pathology 5, 213-221

194. Lucassen P.J. et al. (1995) Detection of apoptosis in murine scrapie. Neuroscience Letters 198, 185-188

195. Jesionek-Kupnicka D. et al. (1997) Programmed cell death (apoptosis) in Alzheimer's disease and Creutzfeldt-Jakob disease. Folia Neuropathologica 35, 233-235

196. Pillot T. et al. (2000) A nonfibrillar form of the fusogenic prion protein fragment [118-135] induces apoptotic cell death in rat cortical neurons. Journal of Neurochemistry 75, 2298-2308

197. O’Donovan C.N., Tobin D. and Cotter T.G. (2001) Prion protein fragment PrP-(106-126) induces apoptosis via mitochondrial disruption in human neuronal SH-SY5Y cells. Journal of Biological Chemistry 276, 43516-43523

198. Lin D.T. et al. (2008) Cytosolic prion protein is the predominant anti-Bax prion protein form: exclusion of transmembrane and secreted prion protein forms in the anti-Bax function. Biochimica et Biophysica Acta 1783, 2001-2012

199. Chiesa R. et al. (2000) Accumulation of protease-resistant prion protein (PrP) and apoptosis of cerebellar granule cells in transgenic mice expressing a PrP insertional mutation. Proceedings of the National Academy of Sciences of the United States of America 97, 5574-5579

200. Coulpier M. et al. (2006) Bax deletion does not protect neurons from BSE-induced death. Neurobiology of Disease 23, 603-611

201. Siso S. et al. (2002) Abnormal synaptic protein expression and cell death in murine scrapie. Acta Neuropathologica 103, 615626

202. Nakagawa T. et al. (2000) Caspase-12 mediates endoplasmicreticulum-specific apoptosis and cytotoxicity by amyloid-beta. Nature 403, 98-103

203. Mansuy I.M. (2003) Calcineurin in memory and bidirectional plasticity. Biochemical and Biophysical Research Communications 311, 1195-1208

204. Steele A.D. et al. (2007) Prion pathogenesis is independent of caspase-12. Prion 1, 243-247

205. Soto C. and Satani N. (2011) The intricate mechanisms of neurodegeneration in prion diseases. Trends in Molecular Medicine 17, 14-24

206. Torres M. et al. (2010) Prion protein misfolding affects calcium homeostasis and sensitizes cells to endoplasmic reticulum stress. PLOS ONE 5, e15658

207. Mukherjee A. et al. (2010) Calcineurin inhibition at the clinical phase of prion disease reduces neurodegeneration, improves behavioral alterations and increases animal survival. PLoS Pathogens 6, e1001138

208. Shmerling D. et al. (1998) Expression of amino-terminally truncated $\mathrm{PrP}$ in the mouse leading to ataxia and specific cerebellar lesions. Cell 93, 203-214

209. Li A. et al. (2007) Neonatal lethality in transgenic mice expressing prion protein with a deletion of residues 105-125. EMBO Journal 26, 548-558

210. Baumann F. et al. (2007) Lethal recessive myelin toxicity of prion protein lacking its central domain. EMBO Journal 26, 538-547

211. Solomon I.H., Schepker J.A. and Harris D.A. (2010) Prion neurotoxicity: insights from prion protein mutants. Current Issues in Molecular Biology 12, 51-61

212. Christensen H.M. et al. (2010) A highly toxic cellular prion protein induces a novel, nonapoptotic form of neuronal death. American Journal of Pathology 176, 2695-2706

213. Orsi A. et al. (2006) Conditions of endoplasmic reticulum stress favor the accumulation of cytosolic prion protein. Journal of Biological Chemistry 281, 30431-30438

214. Rane N.S. et al. (2008) Reduced translocation of nascent prion protein during ER stress contributes to neurodegeneration. Developmental Cell 15, 359-370

215. Kang S.W. et al. (2006) Substrate-specific translocational attenuation during ER stress defines a pre-emptive quality control pathway. Cell 127, 999-1013

216. Drisaldi B. et al. (2003) Mutant PrP is delayed in its exit from the endoplasmic reticulum, but neither wild-type nor mutant PrP undergoes retrotranslocation prior to proteasomal degradation. Journal of Biological Chemistry 278, 2173221743

217. Walter P. and Ron D. (2011) The unfolded protein response: from stress pathway to homeostatic regulation. Science 334, 1081-1086

218. Lindholm D., Wootz H. and Korhonen L. (2006) ER stress and neurodegenerative diseases. Cell Death and Differentiation 13, 385-392

219. Hetz C. et al. (2008) Unfolded protein response transcription factor XBP-1 does not influence prion replication or pathogenesis. Proceedings of the National Academy of Sciences of the United States of America 105, 757-762

220. Teske B.F. et al. (2011) The eIF2 kinase PERK and the integrated stress response facilitate activation of ATF6 during endoplasmic reticulum stress. Molecular Biology of the Cell 22, 4390-4405

221. Hetz C., Castilla J. and Soto C. (2007) Perturbation of endoplasmic reticulum homeostasis facilitates prion replication. Journal of Biological Chemistry 282, 12725-12733 
222. Moreno J.A. et al. (2012) Sustained translational repression by eIF2alpha-P mediates prion neurodegeneration. Nature $\mathbf{4 8 5}$, 507-511

223. Ciechanover A. and Brundin P. (2003) The ubiquitin proteasome system in neurodegenerative diseases: sometimes the chicken, sometimes the egg. Neuron 40, 427-446

224. Ma J. and Lindquist S. (2002) Conversion of PrP to a self-perpetuating PrPSc-like conformation in the cytosol. Science 298, 1785-1788

225. Yedidia Y. et al. (2001) Proteasomes and ubiquitin are involved in the turnover of the wild-type prion protein. EMBO Journal 20, 5383-5391

226. Lowe J. et al. (1992) Immunoreactivity to ubiquitin-protein conjugates is present early in the disease process in the brains of scrapie-infected mice. Journal of Pathology 168, 169-177

227. Ironside J.W. et al. (1993) Ubiquitin immunocytochemistry in human spongiform encephalopathies. Neuropathology and Applied Neurobiology 19, 134-140

228. Kovacs G.G. et al. (2005) Subcellular localization of diseaseassociated prion protein in the human brain. American Journal of Pathology 166, 287-294

229. Kang S.C. et al. (2004) Prion protein is ubiquitinated after developing protease resistance in the brains of scrapie-infected mice. Journal of Pathology 203, 603-608

230. Kristiansen M. et al. (2005) Disease-related prion protein forms aggresomes in neuronal cells leading to caspase activation and apoptosis. Journal of Biological Chemistry 280, 38851-38861

231. Kristiansen M. et al. (2007) Disease-associated prion protein oligomers inhibit the $26 \mathrm{~S}$ proteasome. Molecular Cell 26, $175-188$

232. Jamieson E. et al. (2001) Activation of Fas and caspase 3 precedes PrP accumulation in $87 \mathrm{~V}$ scrapie. Neuroreport 12, 3567-3572

233. Quaglio E. et al. (2011) Expression of mutant or cytosolic PrP in transgenic mice and cells is not associated with endoplasmic reticulum stress or proteasome dysfunction. PLOS ONE 6, e19339

234. Lloyd S.E. et al. (2009) HECTD2 is associated with susceptibility to mouse and human prion disease. PLoS Genetics 5, e1000383

235. Jeffrey M. et al. (2009) Prion protein with an insertional mutation accumulates on axonal and dendritic plasmalemma and is associated with distinctive ultrastructural changes. American Journal of Pathology 175, 1208-1217

236. Chiesa R. et al. (2003) Molecular distinction between pathogenic and infectious properties of the prion protein. Journal of Virology 77, 7611-7622

237. Lasmezas C.I. et al. (1996) Strain specific and common pathogenic events in murine models of scrapie and bovine spongiform encephalopathy. Journal of General Virology 77 (Pt 7), 1601-1609

238. Trevitt C.R. and Collinge J. (2006) A systematic review of prion therapeutics in experimental models. Brain 129 (Pt 9), 2241-2265

239. Moreno J.A. et al. (2013) Oral treatment targeting the unfolded protein response prevents neurodegeneration and clinical disease in prion-infected mice. Science Translational Medicine 5, 206ra138

240. Halliday M. et al. (2015) Partial restoration of protein synthesis rates by the small molecule ISRIB prevents neurodegeneration without pancreatic toxicity. Cell Death \& Disease 6, e1672

241. Wisniewski T. and Goni F. (2012) Could immunomodulation be used to prevent prion diseases? Expert Review of AntiInfective Therapy 10, 307-317
242. Roettger Y. et al. (2013) Immunotherapy in prion disease. Nature Reviews Neurology 9, 98-105

243. Schenk D. et al. (1999) Immunization with amyloid-beta attenuates Alzheimer-disease-like pathology in the PDAPP mouse. Nature 400, 173-177

244. Enari M., Flechsig E. and Weissmann C. (2001) Scrapie prion protein accumulation by scrapie-infected neuroblastoma cells abrogated by exposure to a prion protein antibody. Proceedings of the National Academy of Sciences of the United States of America 98, 9295-9299

245. Peretz D. et al. (2001) Antibodies inhibit prion propagation and clear cell cultures of prion infectivity. Nature 412, 739743

246. White A.R. et al. (2003) Monoclonal antibodies inhibit prion replication and delay the development of prion disease. Nature 422, 80-83

247. Goni F. et al. (2005) Mucosal vaccination delays or prevents prion infection via an oral route. Neuroscience 133, 413-421

248. Goni F. et al. (2015) Mucosal immunization with an attenuated Salmonella vaccine partially protects white-tailed deer from chronic wasting disease. Vaccine 33, 726-733

Further Reading, Resources and Contacts

Creutzfeldt - Jakob disease foundation (http: //www.cjdfoundation.org). This organization, founded by family members of people afflicted with TSEs, provides valuable information for researchers, CJD patients and their families.

National Prion Disease Pathology Surveillance Center (http:// www.cjdsurveillance.com). Established in 1997, the surveillance centre monitors the possible occurrence of vCJD in the USA, establishes the diagnosis and precise type of prion diseases, informs caregivers, reports data to the Centers for Disease Control and Prevention (CDC) and the Health Departments to monitor prevalence of prion diseases in the USA, investigates possibly acquired cases, and stores tissues for future research studies.

The National CJD Research and Surveillance Unit (http://www. cjd.ed.ac.uk). CJD surveillance in the United Kingdom (UK) was initiated in 1990. This unit has two principal, interrelated functions: CJD surveillance in the UK and research into prion disease and related problems. They operate in close collaboration with the UK Health Departments, the National Blood Authorities, the Health Protection Agency (HPA) and Health Protection Scotland (HPS), as well as local public health teams.

World Organization for Animal Health (OIE) (http://www.oie. int/en/animal-health-in-the-world/bse-specific-data/).

Established in the eighties, this organization dedicates a web page to the BSE situation in the world.

WHO manual for surveillance of human transmissible spongiform encephalopathies including variant Creutzfeldt-Jakob disease (http://whqlibdoc.who.int/publications/2003/ 9241545887.pdf)

*Corresponding author:

Paula Saá,

Scientific Affairs, Holland Laboratory,

American Red Cross,

Rockville, MD, USA.

E-mail: Paula.Saa@redcross.org 